\title{
PEDV enters cells through clathrin-, caveolae-, and lipid raft-mediated endocytosis and traffics via the endo-/lysosome pathway
}

\author{
Xiaona Wei, Gaoli She, Tingting Wu, Chunyi Xue and Yongchang Cao* ${ }^{*}$
}

\begin{abstract}
With the emergence of highly pathogenic variant strains, porcine epidemic diarrhea virus (PEDV) has led to significant economic loss in the global swine industry. Many studies have described how coronaviruses enter cells, but information on PEDV invasion strategies remains insufficient. Given that the differences in gene sequences and pathogenicity between classical and mutant strains of PEDV may lead to diverse invasion mechanisms, this study focused on the cellular entry pathways and cellular transport of the PEDV GI and GIl subtype strains in Vero cells and IPEC-J2 cells. We first characterized the kinetics of PEDV entry into cells and found that the highest invasion rate of PEDV was approximately $33 \%$ in the IPEC-J2 cells and approximately $100 \%$ in the Vero cells. To clarify the specific endocytic pathways, systematic research methods were used and showed that PEDV enters cells via the clathrin- and caveolae-mediated endocytosis pathways, in which dynamin II, clathrin heavy chain, Eps15, cholesterol, and caveolin-1 were indispensably involved. In addition, lipid raft extraction assay showed that PEDV can also enter cells through lipid raft-mediated endocytosis. To investigate the trafficking of internalized PEDV, we found that PEDV entry into cells relied on low pH and internalized virions reached lysosomes through the early endosome-late endosome-lysosome pathway. The results concretely revealed the entry mechanisms of PEDV and provided an insightful theoretical basis for the further understanding of PEDV pathogenesis and guidance for new targets of antiviral drugs.
\end{abstract}

\section{Introduction}

As a type of alphacoronavirus, porcine epidemic diarrhea virus (PEDV) has caused enormous economic loss to the global pork industry, especially after the emergence of highly pathogenic PEDV variant strains in 2010. PEDV was first reported in 1971 in the UK [1], and afterward was also discovered in Europe and Asia [2-5]. Although PEDV has persisted in Asian swine-producing countries, it does not attract enough global attention. After October 2010, severe PED outbreaks occurred even in Chinese pig farms that were already vaccinated with CV777inactivated or live-attenuated vaccines [2, 6-8]. In 2013,

*Correspondence: xuecy@mail.sysu.edu.cn; caoych@mail.sysu.edu.cn State Key Laboratory of Biocontrol, School of Life Sciences, Sun Yat-sen University, Guangzhou 510006, People's Republic of China the first PEDV outbreak occurred in the US and rapidly spread across the entire country [9]. Molecular epidemiological results show the genetic differences between classical (GI subtype) and new PEDV variant strains (GII subtype) [2, 3, 5, 6, 8, 9]. PEDV is presently recognized worldwide due to dramatic changes observed in its epidemic character, pathogenic properties, and gene drift [10]. Studies focused on its pathogenesis [11, 12], immune evasion [13] and developing effective vaccines $[14,15]$ are progressing.

A virus is a non-cellular life form that must rely on cells to complete its life cycle. The first step in virus infection is successful entry into cells. Most enveloped viruses enter cells through cellular endocytosis $[16,17]$. The endocytic pathways utilized by viruses vary, including clathrin-mediated endocytosis (CME), caveolaemediated endocytosis, lipid raft-mediated endocytosis, 
and macropinocytosis, among others. CME is the most classical and well-known endocytic pathway utilized by viruses. After binding to cell surface receptors, the virus is packaged by clathrin-coated pits (CCPs) and transported to clathrin-coated vesicles (CCVs), in which virus particles as the "cargo" will be transported to the early endosomes $[18,19]$. Caveolae is a plasma-specific invagination structure with a diameter of $50-100 \mathrm{~nm}$. When viral particles interact with receptors, caveolae coated with caveolin-1 invaginates and pinches off plasma membrane, then the caveolae vesicles mature into caveosomes and deliver "cargoes" to early endosomes [20, 21]. Lipid raft are plasma membrane microdomains enriched in sphingolipids and cholesterol that participate in the lateral organization of the cell surface. Raft-mediated endocytosis is the process of internalization of ligands and receptors by these domains [22].

The mechanisms of some coronaviruses entry into cells have already been studied, such as severe acute respiratory syndrome coronavirus (SARS-CoV), murine hepatitis virus (MHV), and human coronavirus (HCoVs). Entry of SARS-CoV into HepG2 and COS7 cells is clathrindependent while entry into Vero E6 cells is clathrin- and caveolae-independent [23, 24], but the lipid raft plays an important role in the process [25]. MHV entry into cells needs clathrin [26-28], the same as HCoV-NL63 [29]. For $\mathrm{HCoV}-229 \mathrm{E}$, caveolae-mediated endocytosis is utilized to enter human fibroblast cells [30]. SARS-CoV and MHV$\mathrm{CoV}$ can induce continuous micropinocytosis, but this occurs in the later phase during infection and is not associated with virus entry [31]. Coronaviruses enter host cells via various endocytic pathways after viral spike glycoprotein $(S)$ interacts with receptors and then initiates the endocytic process. Internalized viruses are trafficked like cargoes to membrane fusion sites through specific transport routes. Different CoVs have varying fusion sites [32]. The fusion site of the middle east respiratory syndrome coronavirus (MERS-CoV) takes place in the early endosome, while MHV and the feline infectious peritonitis virus (FIPV) are transported to the lysosome to fuse.

Although there have been many studies on the invasion mechanism of CoV, the invasion strategy of PEDV has not yet been fully elucidated. In 2014, Park et al. [33] revealed that PEDV entry followed clathrin-mediated endocytosis and was dependent on a low $\mathrm{pH}$ for successful entry into cells. In their research, one PEDV strain was studied in Vero cells in the presence of trypsin and only the chemical inhibitors and confocal method were used to reveal the PEDV entry. However, there are still important questions to address. Considering that CoVs take advantage of different pathways to enter cells, whether different subtypes of PEDV invade cells by different ways and whether PEDV enter different types of cells through different ways remains to be determined. To concretely clarify the entry and transportation routes of PEDV, we used Vero and IPEC-J2 cells as models for PEDV entry and chose CV777-like strain GDS09 and highly pathogenic variant strain GDS01 to compare the invasion strategies of different PEDV subtypes. Our results will advance the understanding of the pathogenesis and immune evasion of PEDV.

\section{Materials and methods \\ Cells, viruses, reagents, antibodies and plasmids}

Vero cells were cultured in Dulbecco's Modified Eagle Medium (DMEM) supplemented with 10\% fetal bovine serum (FBS, Gibco) and antibiotics $(100 \mathrm{U} / \mathrm{mL}$ penicillin and $100 \mu \mathrm{g} / \mathrm{mL}$ streptomycin). IPEC-J2 cells were grown in DMEM/nutrient mixture F-12 (DMEM/F12) supplemented with 5\% FBS and antibiotics. The PEDV strains used in this study were CV777-like strain GDS09 (GI subtype, Genbank ID: MH726408.1) and highly pathogenic variant strain GDS01 (GII subtype, Genbank ID: KM089829.1). Exogenous trypsin $(10 \mu \mathrm{g} / \mathrm{mL})$ was added to proliferate PEDV strains in Vero cells and $5 \mu \mathrm{g} /$ $\mathrm{mL}$ trypsin was added in IPEC-J2 cells. SBTI (soy bean trypsin inhibitor type I; Sigma No. T6522). The endocytic inhibitors used included dynasore (Sigma-Aldrich, No. 324410), chlorpromazine (CPZ, Sigma-Aldrich, No. C0982), methyl- $\beta$-cyclodextrin (M $\beta C D$, Sigma-Aldrich, No. C4555), nystatin (Sigma-Aldrich, No. 475914), ammonium chloride (NH4Cl, Sigma-Aldrich, No. A9434), and bafilomycin A1 (Baf A1, Sigma-Aldrich, No. 196000). Antibodies against clathrin heavy chain, caveolin 1, EEA1, Rab7, and LAMP1 coupled with secondary goat anti-rabbit Alexa Fluor 488 and goat anti-mouse Alexa Fluor 594 were purchased from Abcam. The mouse anti-PEDV-S monoclonal antibody [34] and anti-PEDV$\mathrm{N}$ polyclonal antibody (prepared in our laboratory) were used in the immunofluorescence analysis and Western blotting analysis, respectively. The overexpression plasmids of wild-type and mutant dynamin II (GFP-Dyn-WT and GFP-Dyn-M), EPS 15 (GFP-EPS15-WT and GFPEPS15-M), and caveolin-1 (GFP-Cav-WT and GFP-CavM) were provided by Prof. Mark McNiven, Mayo Center for Biomedical Discovery (Rochester, MN, USA).

\section{Dependence of PEDV on trypsin}

To investigate the trypsin dependency of PEDV strains, Vero cells were seeded in 6-well plates until confluence. After washed with PBS, cells were infected with PEDV strains at a multiplicity of infection (MOI) of 0.5 with or without trypsin $(10 \mu \mathrm{g} / \mathrm{mL})$ or with trypsin and $25 \mu \mathrm{g} / \mathrm{mL}$ SBTI for $12 \mathrm{~h}$ before the quantification of the viruses by qRT-PCR. 


\section{Dynamics of PEDV internalization}

To test the dynamics of PEDV internalization, Vero or IPEC-J2 cells were seeded in 12-well plates until confluence. The cells were pre-chilled for $10 \mathrm{~min}$ and inoculated with PEDV at a MOI of 0.5 at $4{ }^{\circ} \mathrm{C}$ for $1 \mathrm{~h}$ for virus binding. The cells were washed three times with ice-cold PBS to remove unbounded viruses and immediately warmed to $37{ }^{\circ} \mathrm{C}$ to initiate internalization. After incubation for the indicated time intervals, the cells were treated with proteinase $\mathrm{K}(1 \mathrm{mg} / \mathrm{mL})$ at $4{ }^{\circ} \mathrm{C}$ for $30 \mathrm{~min}$ and then washed with PBS to inactivate and remove the non-internalized PEDV particles. The control cells were then washed with PBS. The cells were collected and subjected to qRT-PCR analysis [34].

\section{Cytotoxicity test and drug treatments}

To test the effect of inhibitors on PEDV internalization, it was necessary to evaluate the cytotoxicity of cell inhibitors. The cells were seeded in 96-well plates at a density of $2 \times 10^{5}$ cell/well, grown for $24 \mathrm{~h}$, and treated with endocytic inhibitors at the indicated concentration for $4 \mathrm{~h}$. Then $10 \mu \mathrm{L}$ of CCK-8 solution was added to each well and incubated at $37{ }^{\circ} \mathrm{C}$ for $1 \mathrm{~h}$. An absorbance of $450 \mathrm{~nm}$ was measured. The experiments were repeated three times independently. The concentration of each used inhibitor did not cause significant cytotoxicity to the cell viability. To test the effect of inhibitors on PEDV internalization, the cells were pre-treated with different concentrations of drugs for $1 \mathrm{~h}$ and then infected with GDS01 or GDS09 strains at MOI $=1$ in the presence of drugs for $1 \mathrm{~h}$. After washing with citrate buffer ( $\mathrm{pH}$ 3.0) [35] and PBS, the cells were incubated with medium containing trypsin for $6 \mathrm{~h}$ or $9 \mathrm{~h}$ at $37{ }^{\circ} \mathrm{C}$ and collected for qRT-PCR and Western blotting analysis, respectively.

\section{qRT-PCR and Western blotting}

The expression of PEDV N protein was detected by qRTPCR and Western blotting with GAPDH as the reference. Total RNA was extracted using TRIzol (Invitrogen) according to the manufacturer's instruction and cDNA was synthesized with a ReverTra Ace qPCR RT Master Mix with gDNA Remover Kit (Toyobo, Osaka, Japan). qPCR reaction was performed using a SYBR Premix Ex Taq II Kit (Takara, Tokyo, Japan) using a Light Cycler 480 real-time PCR system (Roche Diagnostics, Indianapolis, IN, USA). For the Western blotting analysis [36], the cells were washed with PBS and lysed in RIPA lysis buffer on ice for $30 \mathrm{~min}$. After SDS-PAGE electrophoresis, proteins were transferred onto polyvinylidene fluoride (PVDF) membrane via the semidry method and immunoblotted with the corresponding antibodies.

\section{Plasmid and siRNA transfection}

Transfection of Vero cells and IPEC-J2 cells with the overexpression plasmids of wild-type and mutant dynamin II (GFP-Dyn-WT and GFP-Dyn-M), EPS 15 (GFP-EPS15WT and GFP-EPS15-M), and caveolin-1 (GFP-Cav-WT and GFP-Cav-M) were performed using Lipofectamine 2000 (Invitrogen) transfection reagents according to the manufacturer's protocol. The cells were seeded in 12-well plates until $80 \%$ confluence. $24 \mathrm{~h}$ after transfection, the cells were infected with PEDV at MOI $=1$ for $1 \mathrm{~h}$. Virus was moved with citrate buffer and PBS and replaced with fresh medium containing trypsin, and virus internalization was evaluated by confocal fluorescence microscope.

For the RNA interference assay, siRNAs against dynamin II (siDyn, Sus scrofa: 5'-CACCTCATGATC AATAACA-3', Chlorocebus sabaeus 5'-CCTACATCA ACACGAACCA-3'), clathrin heavy chain (siCHC, Sus scrofa 5'-CCCATACCATGACTGATGA-3', Chlorocebus sabaeus $5^{\prime}$-GATGAACCTTATGCATGCA-3'), EPS 15 (siEPS15, Sus scrofa 5'-CCTGTGGATATTCTTGGA A-3', Chlorocebus sabaeus 5'-CCCAGAAACAGCAAG TACA-3'), and caveolin-1 (siCav, Sus scrofa $5^{\prime}$-CAACAT GCAGAAAGAAATA-3', Chlorocebus sabaeus 5'-CCT TCACTGTGACGAAGTA-3') were designed and synthesized based on the corresponding full-length mRNA sequences of Sus scrofa and Chlorocebus sabaeus, siRNAs against Rab7A (siRab7, 5'-GATGGTGGATGACAG ACTA-3'), and VPS39 (siVPS39, 5'-GCTTCAAGAGAG ACTACTA-3') were designed and synthesized based on the corresponding mRNA homologous sequences of Sus scrofa and Chlorocebus sabaeus. The control siRNA (siControl) was designed and synthesized irrelevantly to all the known genes of Sus scrofa and Chlorocebus sabaeus genome, respectively, by RiboBio (Guangzhou, China). The cells were seeded in 12-well plates until $80 \%$ confluence. To ensure transfection efficiency, a second transfection was carried out at $24 \mathrm{~h}$ after the first transfection. At $48 \mathrm{~h}$ post-first transfection, the cells were infected with PEDV at MOI $=1$ for $1 \mathrm{~h}$. Virus was moved with citrate buffer and PBS and replaced with fresh medium containing trypsin, and virus internalization was evaluated by qRT-PCR and Western blotting at $6 \mathrm{hpi}$ and 9 hpi, respectively.

\section{Co-inoculation of cells with PEDV and transferrin or CTB}

Alexa-594 labeled transferrin (Trf) or Alexa-555 labeled cholera toxin B subunit (CTB) were diluted at 1:500 and mixed with $\mathrm{PEDV}$ at $\mathrm{MOI}=10$. The cells were washed three times with PBS and added to the mixture of PEDV and $\operatorname{Trf}$ or CTB at $4{ }^{\circ} \mathrm{C}$ for $1 \mathrm{~h}$ and then incubated at $37^{\circ} \mathrm{C}$ for $30 \mathrm{~min}$ for internalization. After washing with PBS, the cells were fixed, permeabilized, blocked, incubated 
with mouse anti-PEDV-S monoclonal antibody, incubated with Alexa 488-conjugated goat anti-mouse IgG $(\mathrm{H}+\mathrm{L})$, stained with DAPI, and analyzed using a confocal fluorescence microscope. Light exposure was avoided throughout this experiment.

\section{Confocal microscopy}

Cells cultured in glass-bottom dishes for $12 \mathrm{~h}$ were washed with ice-cold PBS and incubated with PEDV at $4{ }^{\circ} \mathrm{C}$ for $1 \mathrm{~h}$. Cold viruses were replaced with pre-warmed medium, and the cells were immediately shifted to $37^{\circ} \mathrm{C}$. At specific time points, the cells were fixed in $4 \%$ paraformaldehyde at RT for 15 min after washing three times with PBS. Permeabilization was carried with $0.5 \%$ Triton X-100 at RT for $15 \mathrm{~min}$. After washing with PBS, the cells were blocked with 5\% BSA in PBST at RT for $60 \mathrm{~min}$ to block unspecific binding sites. The specific primary antibodies against CHC, EEA1, caveolin-1, Rab7, LAMP1, and anti-PEDV-S antibody were used to probe the cells at $4{ }^{\circ} \mathrm{C}$ overnight. The cells were incubated with secondary antibodies (goat anti-rabbit IgG antibody conjugated to Alexa Fluor 488 and goat anti-mouse IgG antibody conjugated to Alexa Fluor 594) at $37^{\circ} \mathrm{C}$ for $1 \mathrm{~h}$. Fluorescent images were acquired using the light-scanning module of a Leica TCS SP8 STED $3 \times$ confocal microscope.

\section{Lipid raft isolation}

The cells $\left(5 \times 10^{7}\right)$ were incubated or not incubated with PEDV at $37^{\circ} \mathrm{C}$ for $1 \mathrm{~h}$, washed three times with ice-cold PBS, and lysed in $1 \mathrm{~mL}$ TNE buffer ( $25 \mathrm{mM}$ Tris, $150 \mathrm{mM}$ $\mathrm{NaCl}, 5 \mathrm{mM}$ EDTA, and $\mathrm{pH}$ 7.5) containing 1\% Triton $\mathrm{X}-100$ and $1 \%$ phenylmethanesulfonyl fluoride (PMSF) on ice for $30 \mathrm{~min}$. The homogenized cell lysates were centrifuged at $4{ }^{\circ} \mathrm{C}$ for $5 \mathrm{~min}$ at $1000 \mathrm{~g}$ and the supernatant was mixed with isometric $1 \mathrm{~mL}$ containing $80 \%$ sucrose in TNE buffer. The lysates-sucrose mixture was placed at the bottom of ultracentrifugal tubes and overlaid with $7 \mathrm{~mL} \mathrm{30 \%} \mathrm{and} 3 \mathrm{~mL} \mathrm{5 \%} \mathrm{sucrose} \mathrm{in} \mathrm{TNE} \mathrm{buffer.} \mathrm{The} \mathrm{cell}$ lysates were ultracentrifuged at $4{ }^{\circ} \mathrm{C}$ for $16 \mathrm{~h}$ at $20000 \mathrm{~g}$ in a SW41 rotor (Beckman). After centrifugation, twelve $1 \mathrm{~mL}$ fractions were collected from the top to the bottom of the tubes. The fractions were concentrated with $6 \%$ PEG at $4{ }^{\circ} \mathrm{C}$ overnight, and the pellets were resuspended in $100 \mu \mathrm{L}$ of TNE buffer after centrifuging at $4{ }^{\circ} \mathrm{C}$ for $30 \mathrm{~min}$ at $10000 \mathrm{~g}$. The localizations of lipid raft-associated protein caveolin-1 and PEDV $\mathrm{N}$ protein were analyzed by Western blotting.

\section{Image and statistical analyses}

All the graphs were created with GraphPad Prism 6 software. All the data are presented as the means \pm standard deviations (SDs) from at least three independent experiments. Significance was estimated using one-way
ANOVA with multiple comparisons to control. $P$ values less than 0.05 were defined as the threshold for statistical significance. $P$ values between 0.05 and 0.01 were marked with one asterisk, $P$ values between 0.01 and 0.001 were marked with two asterisks, $P$ values between 0.001 and 0.0001 were marked with three asterisks, and $P$ values less than 0.0001 were marked with four asterisks.

\section{Results \\ Dependence of PEDV on trypsin}

Coronavirus entry is inextricably linked with proteolytic processing of the $S$ protein. In most cases, PEDV is trypsin dependent. Thus, we investigated the trypsin dependency of both strains used in our research. As shown in Figure 1A, GDS01 strain needed trypsin while GDS09 strain is trypsin independent. So, we added trypsin in the following assays to explore the invasion mechanism of PEDV.

\section{Kinetics of PEDV internalization}

The dynamics of viruses invading different kinds of cells vary, and there may be differences among various subtypes of the same virus. Thus, it is necessary to know the entry dynamics of PEDV before studying the endocytic pathways. The cells were incubated with PEDV at MOI $=0.5$ at $4{ }^{\circ} \mathrm{C}$ for adsorption and shifted to $37{ }^{\circ} \mathrm{C}$ to initiate internalization. The adsorbed but not internalized virions were removed with proteinase $\mathrm{K}$, and the PEDV invasion rates at different time points were detected using qRT-PCR. The invasion kinetics (Figure 1) showed that most of the PEDV particles were detached from the cells by proteinase $\mathrm{K}$ at the beginning of invasion. After $60 \mathrm{~min}$ in the Vero cells (Figure 1B) and $45 \mathrm{~min}$ in the IPEC-J2 cells (Figure 1C), nearly maximum proportions of viral particles completed the internalization. Approximately $95 \%$ of the PEDV particles entered the Vero cells, while only $30 \%$ entered the IPEC-J2 cells. Notably, the GDS01 strain demonstrated less efficient invasion than the GDS09 strain, but there was no significant difference.

\section{PEDV entry involves dynamin II}

Dynamin II plays an essential role in cellular membrane fusion during vesicle formation due to its GTPase activity, and it is necessary for clathrin- and caveolae-mediated endocytosis [35, 37]. Thus, we explored the essentiality of dynamin II in PEDV entry using specific chemical inhibitors, overexpression of domain-negative mutants of dynamin II, and siRNA interference. Dynasore [38], a cell-permeable non-competitive inhibitor of dynamin II, was used to pre-treat cells at different concentrations to analyze the effect on PEDV entry. The cytotoxicity test showed that $50 \mu \mathrm{M}$ of dynasore had no effect on the viability of the Vero and IPEC-J2 cells (Additional file 1). 


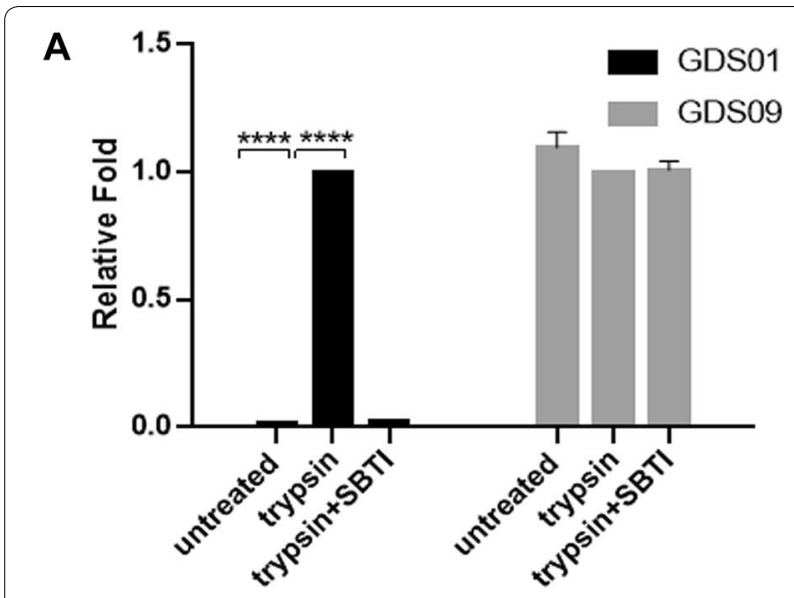

B
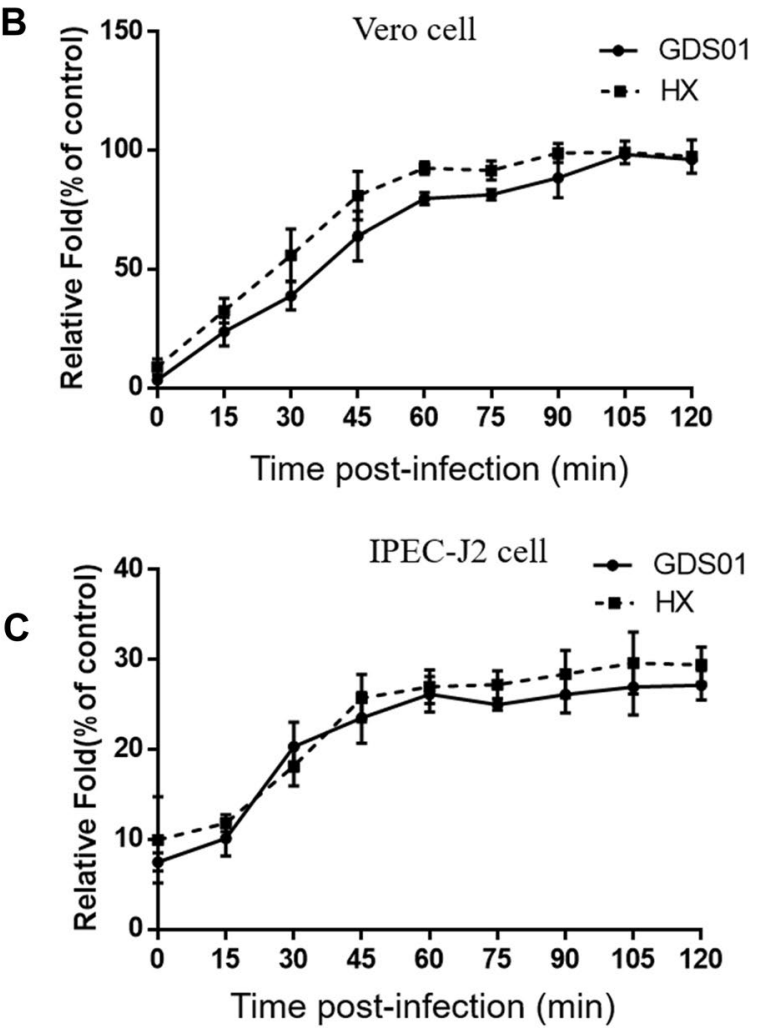

Figure 1 Trypsin-dependency and kinetics of PEDV entry into cells. A Vero cells were seeded in 6-well plates until confluence. Cells were washed with PBS and infected with PEDV strains $(\mathrm{MOI}=0.5)$ without trypsin or in the presence of trypsin $(10 \mu \mathrm{g} / \mathrm{mL})$ or trypsin and $25 \mu \mathrm{g} / \mathrm{mL} \mathrm{SBTI}$. Cells were collected for qRT-PCR at $12 \mathrm{hpi}$. B, C Vero cells (B) and IPEC-J2 cells (C) were incubated with PEDV GDS01 and GDS09 strains, respectively, at $4^{\circ} \mathrm{C}$ for $1 \mathrm{~h}$ and shifted to $37^{\circ} \mathrm{C}$ immediately to initiate internalization. At 0, 15, 30, 45, 60, 75, 90, 105, and $120 \mathrm{~min}$ after incubation, the cells were treated with proteinase $\mathrm{K}$ $\left(1 \mathrm{mg} / \mathrm{mL}\right.$ ) at $4{ }^{\circ} \mathrm{C}$ for $30 \mathrm{~min}$ to inactivate the non-internalized virions. The control cells were washed with PBS. The invasion rates were calculated by qRT-PCR analysis. ${ }^{* * *} P<0.001$.
Cells were pre-treated with $30 \mu \mathrm{M}$ and $50 \mu \mathrm{M}$ dynasore for $1 \mathrm{~h}$ before PEDV infection. DMSO was used as a negative control. The effect of dynasore on PEDV entry was quantified by qRT-PCR at 6 hpi. PEDV invasion was significantly inhibited by dynasore. At a concentration of $50 \mu \mathrm{M}$, the invasion rates of the GDS01 and GDS09 strains into the Vero cells were approximately $17 \%$ and $12 \%$, and the invasion rates into the IPEC-J2 cells were $8 \%$ and $63 \%$, respectively (Figure 2A). A comparison of the invasion rates of the GDS01 and GDS09 strains indicated that the GDS01 strain was more sensitive to dynasore than the GDS09 strain when invading the IPEC-J2 cells but there was no significant difference between them when invading the Vero cells. Many studies used the overexpression of dominant negative mutants to explore the role of dynamin II in virus entry [39, 40]. Mutation of dynamin II from $44 \mathrm{~K}$ to $44 \mathrm{~A}$ can inhibit GTPase activity and reduce endocytosis [41]. Cells were transfected with wild-type and mutant types of dynamin II respectively and infected with GDS01 and GDS09 strains at 24 h after transfection. The confocal results showed that the Vero and IPEC-J2 cells overexpressing wild-type dynamin II (GFP-Dyn-WT) were infected with PEDV while the cells overexpressing mutant dynamin II (GFP-Dyn-M) were barely infected (Figure 2B). siRNA interference was also used to identify the importance of dynamin II on virus entry [23, 35, 42]. Sus scrofa and Chlorocebus sabaeus siRNAs of dynamin II (siDyn) were designed and synthesized. The interference efficiency of siRNA on the dynamin II expression in the Vero and IPEC-J2 cells was obvious at both the mRNA and protein levels (Additional file 1). Cells were infected with PEDV after transfection twice and the internalized virions were quantified at 6 hpi and 9 hpi by qRT-PCR and Western blotting assay, respectively. The qRT-PCR results (Figure $2 \mathrm{C}$ ) showed that the knockdown of dynamin II expression reduced the PEDV internalization. The internalization rates of the GDS01 and GDS09 strains into Vero cells were approximately $50 \%$ and $57 \%$, the internalization rates into the IPEC-J2 cells were approximately $48 \%$ and $60 \%$, respectively, but there was no significant difference between the GDS01 and GDS09 strains in the two cells (Figure 2C). The same results were confirmed by Western blotting (Figure 2D). Taken together, the results suggested that PEDV entry relies on dynamin II.

\section{PEDV entry involves clathrin-mediated endocytosis}

Clathrin-mediated endocytosis is the most commonly used and classical endocytic pathway for virus entry. To identify whether PEDV utilized CME to enter cells, we co-inoculated the Vero and IPEC-J2 cells with PEDV and Trf, which is the most typical biomolecule that uses CME to enter cells [43]. The co-inoculation results 

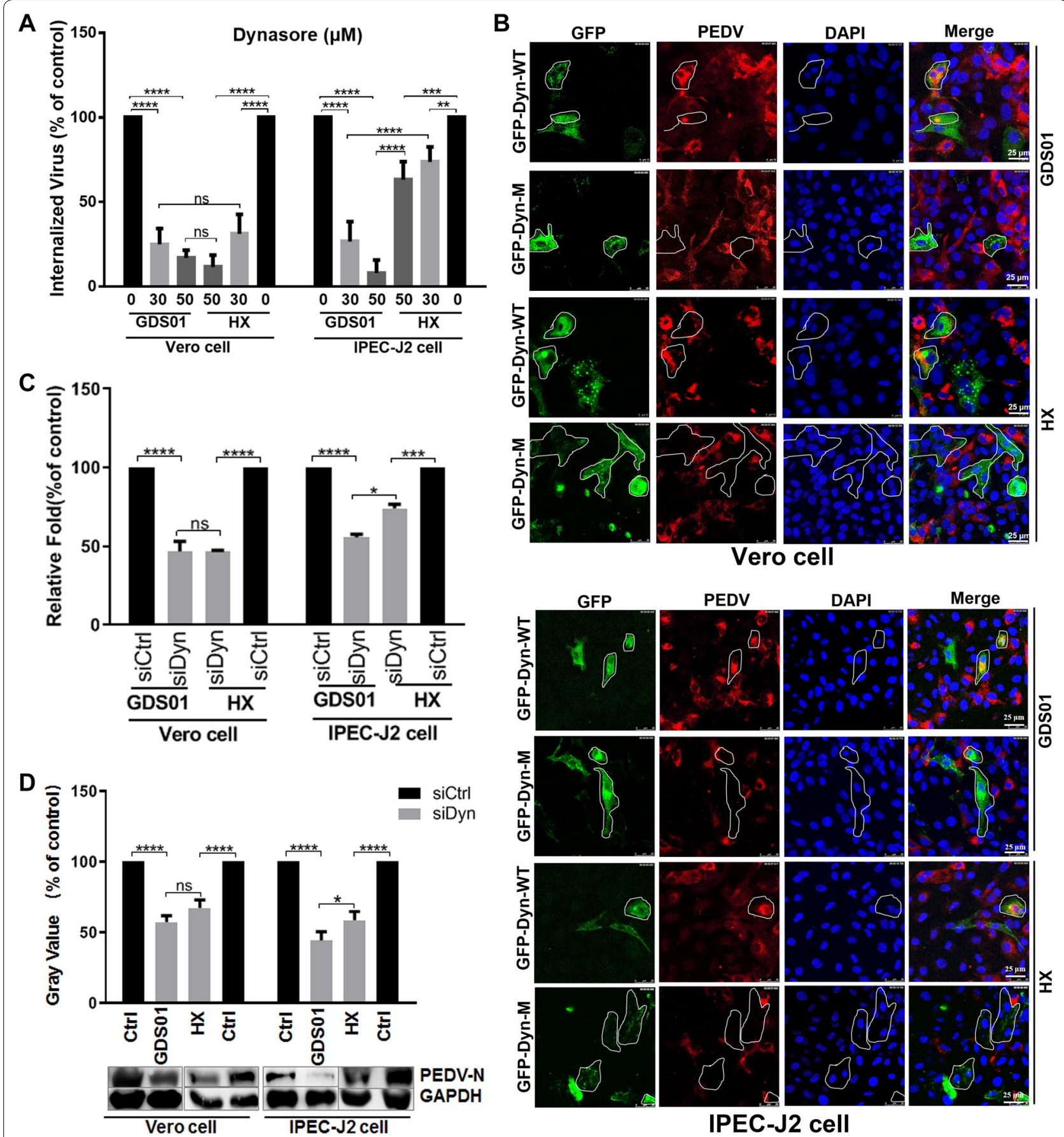

IPEC-J2 cell

Figure 2 Dynamin II involved in PEDV entry. A Cells were pre-treated with $30 \mu \mathrm{M}$ and $50 \mu \mathrm{M}$ dynasore at $37^{\circ} \mathrm{C}$ for $1 \mathrm{~h}$, respectively, and incubated with GDS01 or GDS09 strain for 1 h. DMSO was used as a negative control. The cells were collected at 6 hpi for qRT-PCR assay to test the invasion efficiency of PEDV. B Vero and IPEC-J2 cells were transfected with GFP-Dyn-WT and GFP-Dyn-M, respectively, and infected with PEDV strains at $24 \mathrm{~h}$ after transfection. The cells were fixed at $12 \mathrm{hpi}$ and stained for confocal analysis. C, D Vero and IPEC-J2 cells were transfected with siDyn twice and infected with PEDV strains at $24 \mathrm{~h}$ after the second transfection. The invasion rates of PEDV into the cells were detected at $6 \mathrm{hpi}$ and 9 hpi for qRT-PCR and Western blotting analysis, respectively. Ctrl means control. Scale bars indicate $25 \mu \mathrm{m}$. ${ }^{* *} 0.05<P<0.01 ;{ }^{* * *} 0.01<P<0.001$; **** $P<0.001$. 
showed that PEDV co-located with Trf in the two types of cells (Figure 3A), which means that PEDV might utilize clathrin-mediated endocytosis to enter cells. To prove this conjecture, we used specific chemical inhibition, the overexpression of domain negative mutants of EPS 15, the knockdown expression of CHC and EPS 15 by siRNA, and the location of PEDV in the cells to estimate the role of clathrin-mediated endocytosis in PEDV entry. CPZ is a specific chemical inhibitor used to block the CME pathway by preventing the assembly of CCPs at the plasma membrane [44]. The cytotoxicity test showed that $30 \mu \mathrm{M} \mathrm{CPZ} \mathrm{have} \mathrm{no} \mathrm{effect} \mathrm{on} \mathrm{the} \mathrm{via-}$ bility of the Vero cells and $50 \mu \mathrm{M} \mathrm{CPZ}$ have no effect on the viability of the IPEC-J2 cells (Additional file 2). Vero and IPEC-J2 cells were treated with $\mathrm{CPZ}$ at different concentrations for $1 \mathrm{~h}$ and then infected with PEDV. The internalization rates of PEDV after CPZ treatment were quantified by qRT-PCR and Western blotting at $6 \mathrm{hpi}$ and 9 hpi, respectively. The qRT-PCR results (Figure $3 \mathrm{~B}$ ) showed that PEDV invasion was significantly inhibited by CPZ. The invasion rates of the GDS01 and GDS09 strains at the highest drug concentrations were nearly $48 \%$ and $23 \%$ in the Vero cells and $24 \%$ and $50 \%$ in the IPEC-J2 cells, respectively. Notably, there were no significant differences between the GDS01 and GDS09 strains in the Vero cells but the GDS01 strain was more sensitive than the GDS09 strain in the IPEC-J2 cells, reflecting the GDS01 strain's significantly decreased invasion rates (Figure 3B). The same results were also observed by Western blotting (Figure $3 \mathrm{C}$ ) and IFA assay (Additional files 3,4). The role of CME in endocytosis was also identified by the overexpression of GFP-tagged dominant negative mutants of EPS 15 [45]. EPS 15 is a critical component of CCPs by interacting with adaptor protein 2 (AP-2), a major clathrin adaptor complex [46]. Cells transfected with wild-type (GFP-EPS15WT) and mutant EPS 15 (GFP-EPS15-M) were infected with PEDV strains at $24 \mathrm{~h}$ after transfection. The confocal results of the PEDV invasion showed that the cells overexpressing wild-type EPS 15 were infected with PEDV while few infections were observed in the overexpressed GFP-EPS15-M cells (Figure 3D). siRNA was also used to explore the role of CME in PEDV entry by interfering with the expression of clathrin heavy chain $(\mathrm{CHC})$ and EPS 15. CHC and clathrin light chain form a triskelion shape, which is a key component for regulating the formation and disassembly of the clathrin lattice [47]. Cells were infected with PEDV strains after transfection twice, and the invasion rates of the viruses were assessed using qRT-PCR and Western blotting assay at $6 \mathrm{hpi}$ and $9 \mathrm{hpi}$, respectively. The quantitative experiments showed that knockdown of the expression of $\mathrm{CHC}$ significantly reduced the invasion rates of PEDV. The invasion rates of the GDS01 and GDS09 strains were $50 \%$ and $62 \%$ in the Vero cells and $61 \%$ and $65 \%$ in the IPEC-J2 cells, respectively, and there was no significant difference between the GDS01 and GDS09 strains (Figure 3E). Knockdown of the expression of EPS 15 also significantly reduced the invasion rates of PEDV. The invasion rates of the GDS01 and GDS09 strains were $61 \%$ and $65 \%$ in the Vero cells and $51 \%$ and $66 \%$ in the IPEC-J2 cells, respectively, and there was no significant difference between the GDS01 and GDS09 strains (Figure 3G). The significant inhibition of siCHC and siEPS15 on PEDV entry was also observed by Western blotting assay (Figures 3F, H). To estimate whether PEDV directly entered the cells through CME, we analyzed the localization of PEDV and $\mathrm{CHC}$ in the Vero and IPEC-J2 cells, respectively. Pre-cooled cells were incubated with PEDV at $4{ }^{\circ} \mathrm{C}$ for $1 \mathrm{~h}$ for adsorption and shifted to $37{ }^{\circ} \mathrm{C}$ for internalization. Five min later, the cells were washed and fixed for observation using an ultrahigh-resolution laser confocal microscope. The confocal results showed that PEDV particles co-located with CHC protein in the Vero and IPEC-J2 cells (Figure 3I), but some virions were not co-localized with $\mathrm{CHC}$. The results indicated that PEDV can enter cells through the CME pathway, but CME may not be the only pathway utilized by PEDV.

\section{PEDV entry relies on cholesterol}

Cholesterol, an important component of cell membranes, embeds phospholipid bilayers and plays a crucial role in the fluidity of cell membranes [48]. Many studies showed that most enveloped virus relied on cholesterol to invade cells $[49,50]$. If a virus invades cells, depending on the presence of cholesterol, it will be sensitive to cholesterol extractants. $\mathrm{M} \beta \mathrm{CD}$ can eliminate cholesterol on the plasma membrane of cells [51]. Nystatin can bind to the cholesterol-enriched regions of cell membrane and then decompose cholesterol and impair cholesterol synthesis [52]. The cytotoxicity test showed that the maximum tolerance concentrations of Vero and IPEC-J2 cells to $\mathrm{M} \beta C D$ were $3 \mathrm{mM}$ and $1.5 \mathrm{mM}$, respectively, and the maximum tolerance concentrations to nystatin were $30 \mu \mathrm{M}$ and $50 \mu \mathrm{M}$, respectively (Additional file 5). Cells were pre-treated with different concentrations of $\mathrm{M} \beta C D$ and nystatin for $1 \mathrm{~h}$, then infected with PEDV. The effects of drugs on PEDV entry were estimated by qRT-PCR and Western blotting at $6 \mathrm{hpi}$ and $9 \mathrm{hpi}$, respectively. M $\mathrm{CCD}$ showed a significant inhibition of PEDV entry. The internalization rates of the GDS01 and GDS09 strains after $\mathrm{M} \beta C D$ treatment were approximately $4 \%$ and $6 \%$ in the Vero cells and approximately 5\% and 35\% in the IPEC-J2 cells. There were no significant differences between the GDS01 and GDS09 strains in the MBCD-treated Vero 

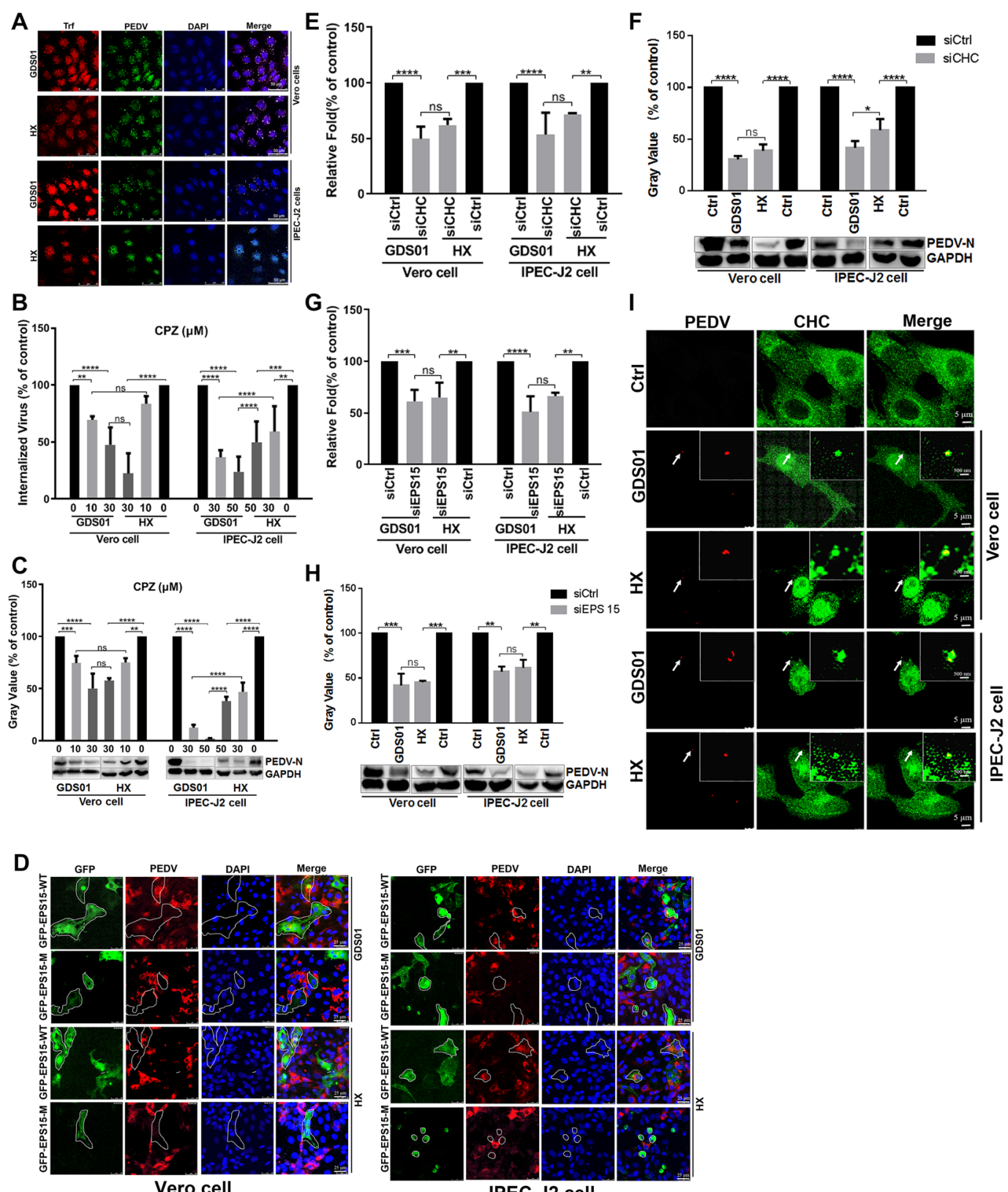

IPEC-J2 cell

Figure 3 PEDV entry relies on the CME pathway. A Vero cells and IPEC-J2 cells were incubated with mixture of Alexa-594 labeled Trf (red) and PEDV (green) at $4{ }^{\circ} \mathrm{C}$ for $1 \mathrm{~h}$, and then shifted to $37^{\circ} \mathrm{C}$ for $30 \mathrm{~min}$. The cells were fixed and stained for PEDV using monoclonal antibody against PEDV S protein. The cellular localizations of Trf and PEDV were observed with a confocal fluorescence microscope. Light exposure was avoided throughout this process. B, C. The Vero cells were pre-treated with $10 \mu \mathrm{M}$ and $30 \mu \mathrm{M}$ of CPZ, and the IPEC-J2 cells were pre-treated with $30 \mu \mathrm{M}$ and $50 \mu \mathrm{M}$ of CPZ, respectively, at $37^{\circ} \mathrm{C}$ for $1 \mathrm{~h}$ and incubated with GDS01 or GDS09 strains for $1 \mathrm{~h}$. Double-distilled water was used as a negative control. The cells were collected at $6 \mathrm{hpi}$ and $9 \mathrm{hpi}$ for qRT-PCR and Western blotting assay, respectively, to test the invasion efficiency of PEDV. D The Vero cells (left) and IPEC-J2 cells (right) were transfected with GFP-EPS15-WT and GFP-EPS15-M, respectively, and infected with PEDV strains at $24 \mathrm{~h}$ after transfection. The cells were fixed at $12 \mathrm{hpi}$ and stained for confocal analysis. E-H The Vero cells and IPEC-J2 cells were transfected with siCHC and siEPS 15 and infected with PEDV strains at $24 \mathrm{~h}$ after the second transfection. The cells were collected at $6 \mathrm{hpi}$ and $9 \mathrm{hpi}$ for qRT-PCR and Western blotting analysis, respectively. I The cells were pre-cooled at $4{ }^{\circ} \mathrm{C}$ for $15 \mathrm{~min}$, incubated with PEDV strains at $4{ }^{\circ} \mathrm{C}$ for $1 \mathrm{~h}$, shifted to $37^{\circ} \mathrm{C}$ for 5 min to initiate internalization, and washed for three times to remove un-internalized viral particles. The cells were fixed and stained with anti-PEDV-S (red) and anti-CHC (green) primary antibodies. Ctrl means control. Scale bars indicate $50 \mu \mathrm{m}$ in $\mathbf{A}, 25 \mu \mathrm{m}$ in $\mathbf{D}$, and $5 \mu \mathrm{m}$ in $\mathbf{I}$. ${ }^{* *} 0.05<P<0.01 ;{ }^{* * *} 0.01<P<0.001 ;{ }^{* * *} P<0.001$ 
cells but in the IPEC-J2 cells, the GDS01 strain was more sensitive to $M \beta C D$ (Figure $4 A$ ). The results were confirmed by Western blotting (Figure 4B) and IFA assay (Additional files 3 and 4). PEDV entry was significantly inhibited by nystatin treatment. The internalization rates of the GDS01 and GDS09 strains after nystatin treatment were approximately $75 \%$ and $25 \%$ in the Vero cells and approximately $65 \%$ and $45 \%$ in the IPEC-J2 cells. The GDS09 strain was more sensitive to nystatin than the GDS01 strain in both the Vero and IPEC-J2 cells (Figure 4C). The same results were confirmed by Western blotting (Figure 4D) and IFA assay (Additional files 3 and 4). To further evaluate the importance of cholesterol, cells pre-treated with $\mathrm{M} \beta C D$ were supplemented with exogenous cholesterol and then infected with PEDV, and the changes in the viral invasion rates were quantified by qRT-PCR at 6 hpi. The results showed that adding exogenous cholesterol could significantly increase the invasion rate of PEDV. The average invasion rate of the GDS01 and GDS09 strains increased from $10 \%$ to over $90 \%$ in the Vero cells and from $10 \%$ and $50 \%$ to approximately 95\% in the IPEC-J2 cells (Figure 4E). The results indicated that PEDV invading and entering cells depended on cholesterol but the two PEDV subtypes showed different degrees of dependence on cholesterol when entering the Vero and IPEC-J2 cells.

\section{PEDV entry involves caveolae-mediated endocytosis}

As both caveolae and lipid raft are rich in cholesterol, they are sensitive to cholesterol inhibitors [53, 54]. To identify whether caveolae-mediated endocytosis was involved in PEDV entry, cells were co-inoculated with PEDV and CTB, which entered the cells after interactions with specific receptors [55]. The localization results showed that PEDV co-localized with CTB in Vero and IPEC-J2 cells (Figure 5A), which means PEDV may utilize caveolae-mediated endocytosis to enter cells. As the caveolae is mainly coated with caveolin-1 [56], knocking down the expression and separating the interaction factors with caveolin-1 blocked the caveolae-mediated endocytic pathway. Overexpression of the domain-negative mutant of caveolin-1 [57] blocked its interaction with the interaction factors. Cells were transfected with wild-type caveolin-1 (GFP-Cav-WT) and mutant caveolin-1 (GFP-Cav-M), then infected with PEDV at $24 \mathrm{~h}$ after transfection, and fixed for confocal observation at $12 \mathrm{hpi}$. The results showed that PEDV infected GFPCav-WT-overexpressing cells but barely infected GFPCav-M-overexpressing Vero or IPEC-J2 cells (Figure 5B). siRNAs (siCav) were designed and synthetized to knockdown caveolin-1 expression. Cells were transfected with siCav twice and then infected with PEDV. After the second transfection, the invasion rates of PEDV were measured by qRT-PCR and Western blotting at $6 \mathrm{hpi}$ and 9 hpi, respectively. The qRT-PCR results showed that the knockdown of caveolin-1 expression reduced the internalization of PEDV. The inhibition rates in the GDS01 and GDS09 strains were 53\% and 32\% in the Vero cells and $33 \%$ and $40 \%$ in the IPEC-J2 cells, respectively (Figure 5C). Compared with the GDS09 strain, the GDS01 strain showed a higher degree of reduction in the invasion rate in the Vero cells but there was no significant difference in the IPEC-J2 cells (Figure 5C). The same results were confirmed by Western blotting assay (Figure 5D). To identify the role of caveolae in PEDV entry, we investigated the cellular localization of PEDV with caveolin-1. Pre-cooled cells were incubated with PEDV at $4{ }^{\circ} \mathrm{C}$ and then shifted to $37{ }^{\circ} \mathrm{C}$ for internalization. The cells were then washed and fixed for $10 \mathrm{~min}$ for observation with an ultrahigh-resolution laser confocal microscope. The cellular localization results showed that PEDV was colocated with caveolin-1 in the Vero and IPEC-J2 cells (Figure 5E). PEDV can enter cells through the caveolaemediated pathway.

\section{PEDV entry involves lipid raft-mediated endocytosis}

If PEDV can enter cells through the lipid raft pathway, the viral components should be contained in lipid raft enrichment layer after isolated by sucrose density gradient centrifugation [58]. After incubation with PEDV, the cells were lysed and subjected to sucrose gradient centrifugation. The products were extracted from the top down and a total of 12 fractions were obtained for Western blotting analysis. Caveolin-1 was used as the protein marker representing the lipid raft layer [58]. The results showed that PEDV could be detected in the upper lipid raft enrichment layer. Almost all the virions were concentrated in the lipid raft enrichment layer in the Vero cells (Figure 6A) and virions were detected in both the upper and lower components in the IPEC-J2 cells (Figure 6B). The differences between the GDS01 and GDS09 strains were the proportion of virions in the upper and lower components in the IPEC-J2 cells. The GDS01 particles were mainly present in the upper layer while amounts of GDS09 particles were present in the lower layer (Figure 6B). The results indicated that PEDV utilized lipid rafts to enter cells.

\section{PEDV entry requires low $\mathrm{pH}$}

Viruses that enter cells via endocytosis are usually trafficked by endocytic vesicles to early endosomes for sorting and are transported to late endosomes or fused with early endosomes [59]. If viruses do not fuse in the early endosomes and release genomes into the cytoplasm, they will enter the late endosomes with the further acidification and maturation of the early endosomes. Similarly, 

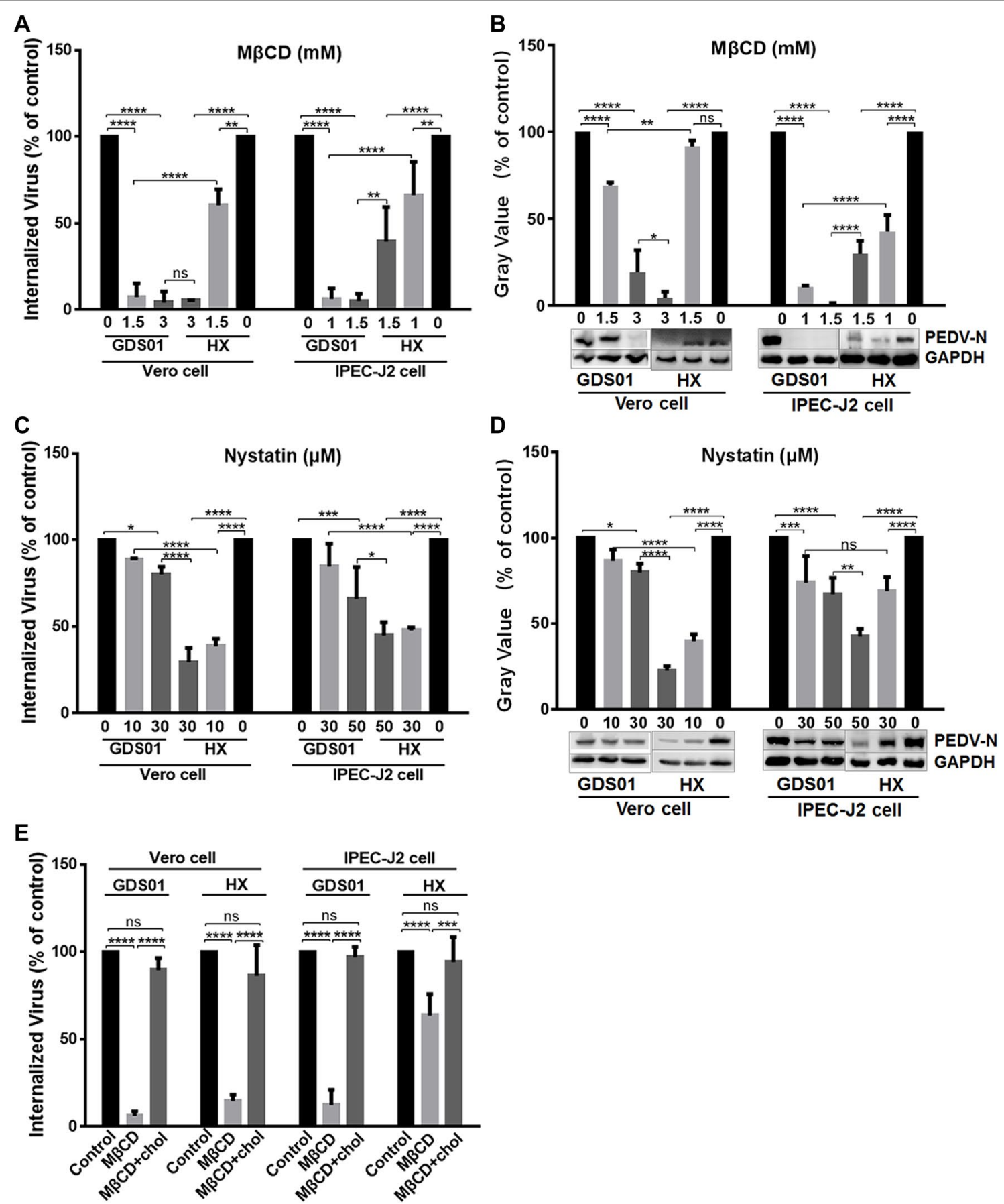

Figure 4 PEDV entry relies on cholesterol. A, B Vero cells and IPEC-J2 cells were pre-treated with $1.5 \mathrm{mM}$ and $3 \mathrm{mM}$ and $1 \mathrm{mM}$ and $1.5 \mathrm{mM} \mathrm{M \beta CD}$, respectively, at $37^{\circ} \mathrm{C}$ for $1 \mathrm{~h}$ and incubated with GDS01 or GDS09 strains for $1 \mathrm{~h}$. Double-distilled water was used as a negative control. The cells were collected at $6 \mathrm{hpi}$ and $9 \mathrm{hpi}$ for qRT-PCR and Western blotting assay, respectively, to test the invasion efficiency of PEDV. C, D The Vero cells and IPEC-J2 cells were pre-treated with $10 \mu \mathrm{M}$ and $30 \mu \mathrm{M}$ and $30 \mu \mathrm{M}$ and $50 \mu \mathrm{M}$ of nystatin, respectively, at $37^{\circ} \mathrm{C}$ for $1 \mathrm{~h}$ and incubated with GDS01 or GDS09 strains for 1 h. DMSO was used as a negative control. The cells were collected at 6 hpi and 9 hpi for qRT-PCR and Western blotting assay, respectively, to test the invasion efficiency of PEDV. E The Vero cells and IPEC-J2 cells were pre-treated with different concentrations of $M \beta C D$ at $37^{\circ} \mathrm{C}$ for $1 \mathrm{~h}$, supplemented with $400 \mu \mathrm{g} / \mathrm{mL}$ of soluble cholesterol at $37^{\circ} \mathrm{C}$ for $1 \mathrm{~h}$, and infected with PEDV strains for $1 \mathrm{~h}$. The cells were collected at $6 \mathrm{hpi}$ for qRT-PCR assay to test the invasion efficiency of PEDV. ${ }^{*} P<0.05 ;{ }^{* *} 0.05<P<0.01 ;{ }^{* * *} 0.01<P<0.001$; ${ }^{* * * *} P<0.001$ 

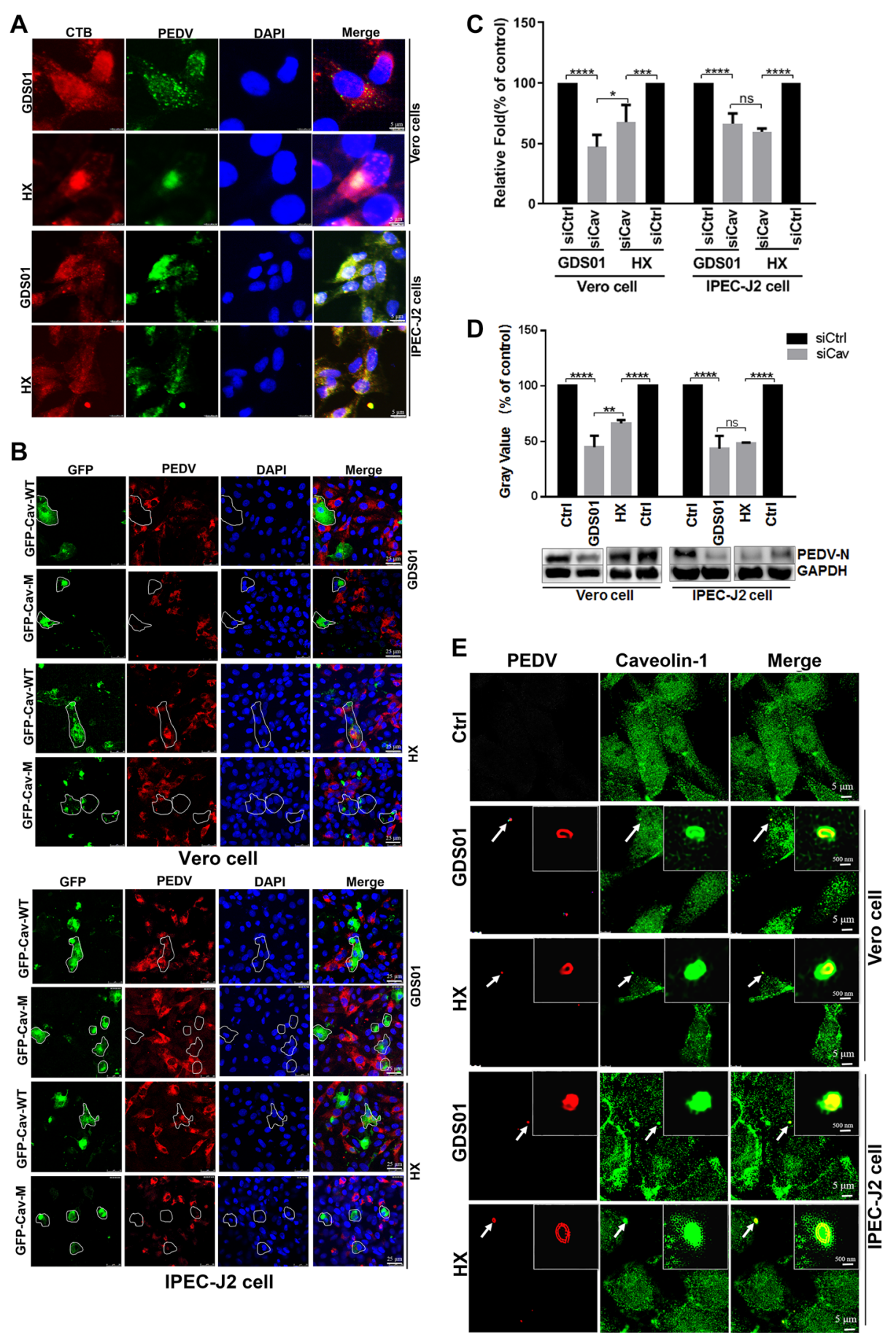

Figure 5 PEDV enters cells through the caveolae-mediated pathway. A Vero cells and IPEC-J2 cells were incubated with a mixture of Alexa-555 labeled CTB (red) and PEDV (green) at $4{ }^{\circ} \mathrm{C}$ for $1 \mathrm{~h}$, and then shifted to $37^{\circ} \mathrm{C}$ for $30 \mathrm{~min}$. The cells were fixed and stained for PEDV using monoclonal antibody against $\mathrm{S}$ protein. The cellular localizations of CTB and PEDV were observed with a confocal fluorescence microscope. Light exposure was avoided throughout this process. B Vero cells (up) and IPEC-J2 cells (down) were transfected with wild-type caveolin-1 (GFP-Cav-WT) and domain negative mutant of caveolin-1 (GFP-Cav-M), respectively, and infected them with PEDV strains at $24 \mathrm{~h}$ after transfection. The cells were fixed at $12 \mathrm{hpi}$ and stained for confocal analysis. C, D The Vero cells and IPEC-J2 cells were transfected with siCav twice and infected with PEDV strains at $24 \mathrm{~h}$ after the second transfection. The cells were collected at $6 \mathrm{hpi}$ and $9 \mathrm{hpi}$ for qRT-PCR and Western blotting analysis, respectively. Ctrl means control. E Cells were pre-cooled at $4{ }^{\circ} \mathrm{C}$ for $15 \mathrm{~min}$, incubated with PEDV strains at $4^{\circ} \mathrm{C}$ for $1 \mathrm{~h}$, shifted to $37^{\circ} \mathrm{C}$ to initiate internalization for $10 \mathrm{~min}$, and washed for three times to remove viral particles that were not internalized. The cells were fixed and stained with anti-PEDV-S (red) and anti-caveolin-1 (green) primary antibodies. Scale bars indicate $50 \mu \mathrm{m}$ in $\mathbf{A}, 25 \mu \mathrm{m}$ in $\mathbf{B}$, and $5 \mu \mathrm{m}$ in $\mathbf{E} .{ }^{*} P<0.05$; ${ }^{* *} 0.05<P<0.01 ;{ }^{* * *} 0.01<P<0.001$; $* * * * P<0.001$ 


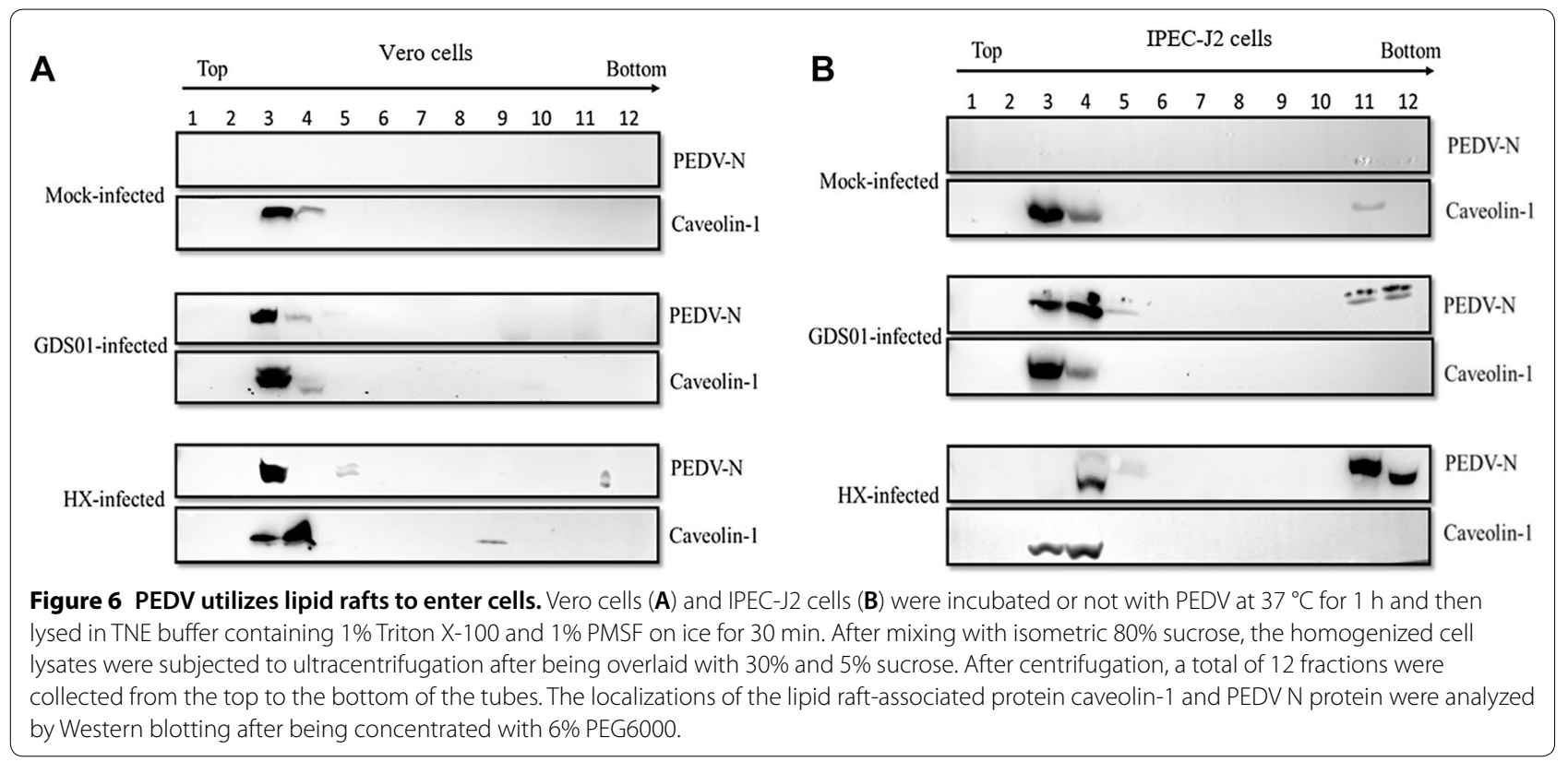

if the $\mathrm{pH}$ environment in the late endosomes does not meet the requirements for conformational changes of viral glycoproteins to cause membrane fusion, viruses will enter the lysosomes with the transportation of the late endosomes and finally achieve membrane fusion. Viruses require acidic $\mathrm{pH}$ to traffic between endosomes. Therefore, it is necessary to clarify whether PEDV relies on a low $\mathrm{pH}$ environment. $\mathrm{NH} 4 \mathrm{Cl}$ is an inhibitor of endosome acidification [60]. Baf A1 is a V-ATPase inhibitor that can block the traffic of endocytic cargoes from early endosomes to late endosomes and inhibit the stability of low $\mathrm{pH}$ environments in the lysosome lumen [61]. Cells were pre-treated with different concentrations of $\mathrm{NH} 4 \mathrm{Cl}$ and Baf A1 (Additional file 6) and infected with PEDV (Additional file 4). The invasion rates of PEDV were measured by qRT-PCR and Western blotting at $6 \mathrm{hpi}$ and 9 hpi, respectively. The results showed that cells pretreated with $\mathrm{NH} 4 \mathrm{Cl}$ significantly inhibited PEDV entry. The invasion rates in the GDS01 and GDS09 strains were approximately $30 \%$ and $15 \%$ in the Vero cells and $50 \%$ and $73 \%$ in the IPEC-J2 cells (Figure 7A). This significant inhibition was also confirmed by Western blotting (Figure 7B) and IFA assay (Additional files 3 and 4). Baf A1 can significantly inhibit PEDV entry. The invasion rates in the GDS01 and GDS09 strains were approximately $75 \%$ and $5 \%$ in the Vero cells and $41 \%$ and $30 \%$ in the IPEC-J2 cells (Figure 7C). Western blotting (Figure 7D) and IFA assay (Additional files 3,4) also confirmed the inhibition of Baf A1. The results proved that PEDV entry requires low $\mathrm{pH}$.
Internalized PEDV is trafficked to lysosomes via endosomes Early endosomes mature into late endosomes by increasing intraluminal acidity through proton pump activity. Late endosomes can become larger vesicles by fusing with the same type of endosomes, so they mostly exist in the form of a multivesicular body (MVB). Late endosomes release Rab5, incorporate Rab7, and prepare to fuse with lysosomes [62]. To explore whether PEDV particles are trafficked after internalization, we interfered with the expression of Rab7 [63] involved in late endosomes and VPS39 [32] involved in late endosometo-lysosome maturation and identified whether viral particles co-located with early endosomes, late endosomes and lysosomes. Knockdown of the expression of Rab7 (siRab7) can significantly inhibit the invasion efficiency of PEDV. The invasion rates of the GDS01 and GDS09 strains were $49 \%$ and $51 \%$ in the Vero cells and $82 \%$ and $38 \%$ in the IPEC-J2 cells (Figure 8A). Similarly, the knockdown of the expression of VPS39 (siVPS39) also significantly inhibited the invasion efficiency of PEDV. The invasion rates of the GDS01 and GDS09 strains were $68 \%$ and $56 \%$ in the Vero cells and $45 \%$ and $50 \%$ in the IPEC-J2 cells (Figure 8B). For cellular location by PEDV observation, pre-cooled cells were incubated with PEDV at $4{ }^{\circ} \mathrm{C}$ and then shifted to $37{ }^{\circ} \mathrm{C}$ for internalization. The cells were washed and fixed at different time points after shift for observation using an ultrahigh-resolution laser confocal microscope. Cellular localization assays showed that internalized PEDV could co-locate with EEA1, the early endosome protein marker, in the Vero 

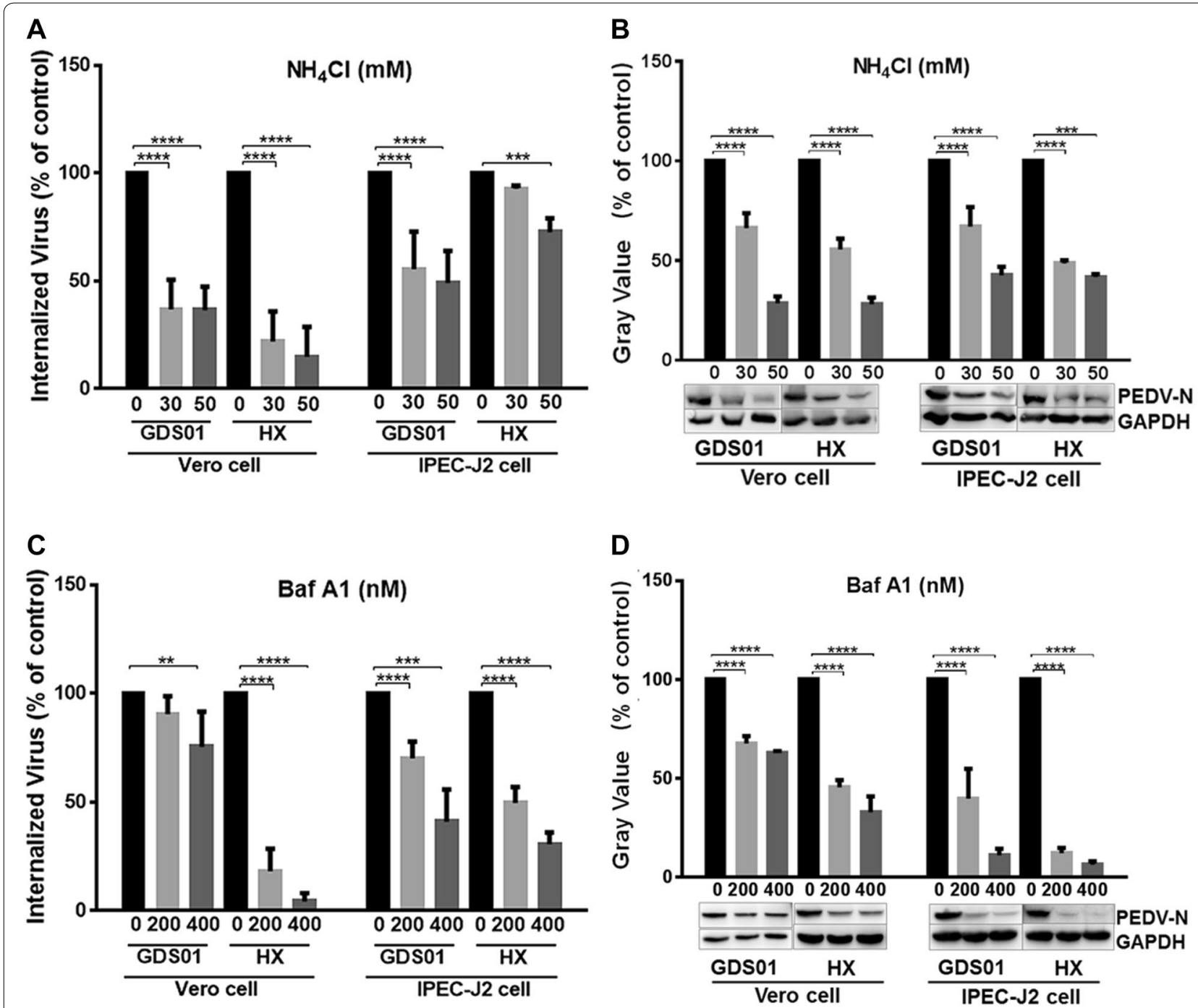

Figure 7 PEDV entry requires low $\mathbf{p H}$. A, B Vero cells and IPEC-J2 cells were pre-treated with $30 \mathrm{mM}$ and $50 \mathrm{mM} \mathrm{NH} 4 \mathrm{Cl}$ at $37^{\circ} \mathrm{C}$ for $1 \mathrm{~h}$ and then incubated with GDS01 or GDS09 strains for 1 h. Double-distilled water was used as a negative control. The cells were collected 6 hpi and 9 hpi for qRT-PCR and Western blotting assay, respectively, to test the invasion efficiency of PEDV. C, D The Vero cells and IPEC-J2 cells were pre-treated with $200 \mathrm{nM}$ and $400 \mathrm{nM} \mathrm{Baf} \mathrm{A1}$ at $37^{\circ} \mathrm{C}$ for $1 \mathrm{~h}$ and then incubated with GDS01 or GDS09 strains for $1 \mathrm{~h}$. DMSO was used as a negative control. The cells were collected $6 \mathrm{hpi}$ and $9 \mathrm{hpi}$ for qRT-PCR and Western blotting assay, respectively, to test the invasion efficiency of PEDV. ${ }^{* *} 0.05<P<0.01$; ${ }^{* * *} 0.01<P<0.001 ;{ }^{* * *} P<0.001$.

and IPEC-J2 cells 30 min after endocytosis (Figure 8C) and could co-locate with Rab7, the late endosome protein marker, $40 \mathrm{~min}$ after endocytosis (Figure 8D), while the late endosomes were mostly in the form of MVB. Colocalization of PEDV with LAMP1 (lysosomal associated membrane protein 1), an important lysosome membrane component, was also observed $50 \mathrm{~min}$ after endocytosis in the two types of cells (Figure 8E). The results demonstrated that PEDV was trafficked to the lysosomes after entering the cells through endocytosis, and there were no differences between the two PEDV genotypes and cells.

\section{Discussion}

Since highly pathogenic variant strains emerged in 2010, PEDV has attracted global attention. Many studies have reported that vaccines based on CV777 or CV777-like strains have low protection efficiency against re-emerging variant strains $[3,4,6-8]$. Genotyping showed that PEDV strains can be sorted into two genotypes, GI subtypes (classical) and GII subtypes (variant). The nucleotide sequence of S1 subunit of $S$ protein is $75-90 \%$ similar between GI and GII, which shows high variability $[10,64]$. As the main antigen of PEDV, the $S$ protein 


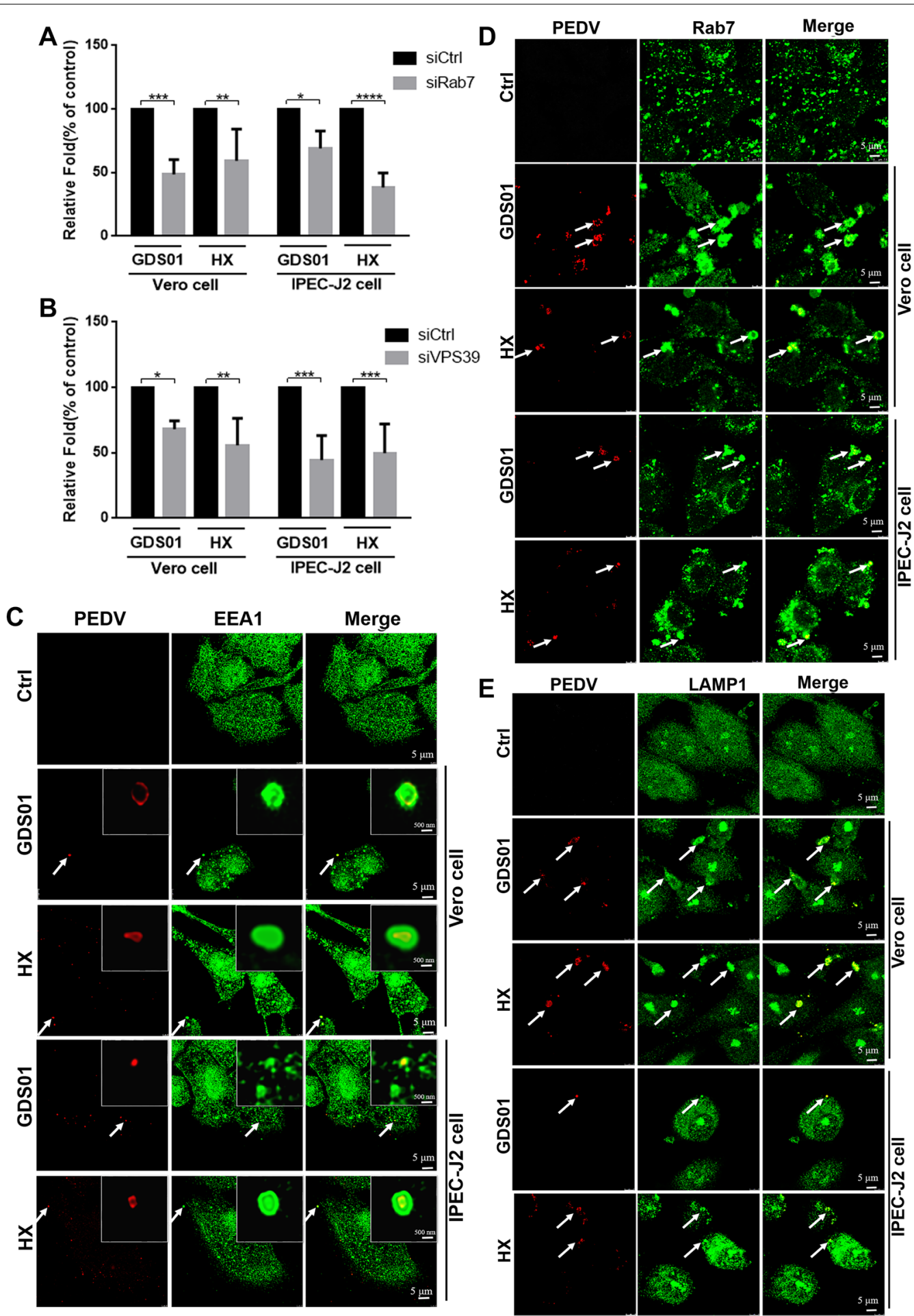

Figure 8 PEDV traffics to lysosome via endosomes. A, B Vero cells and IPEC-J2 cells were transfected with siRab7 and siVPS39 twice, respectively, and then infected with PEDV strains at $24 \mathrm{~h}$ after the second transfection. The cells were collected at $6 \mathrm{hpi}$ for qRT-PCR analysis. Ctrl means control. C-E The Vero cells and IPEC-J2 cells were pre-cooled at $4{ }^{\circ} \mathrm{C}$ for $15 \mathrm{~min}$, incubated with PEDV strains at $4{ }^{\circ} \mathrm{C}$ for $1 \mathrm{~h}$, shifted to $37^{\circ} \mathrm{C}$ to initiate internalization. The non-internalized viral particles were removed by washing. $30 \mathrm{~min}$ after shifting, the cells were fixed and stained with anti-PEDV-S (red) and anti-EEA1 (green) primary antibodies (C). 40 min after shifting, the cells were fixed and stained with anti-PEDV-S (red) and anti-Rab7 (green) primary antibodies (D). 50 min after shifting, the cells were fixed and stained with anti-PEDV-S (red) and anti-LAMP1 (green) primary antibodies (E). Scale bars indicate $5 \mu \mathrm{m}$ in $\mathbf{C}-\mathbf{E} .{ }^{*} P<0.05 ;{ }^{* *} 0.05<P<0.01 ;{ }^{* *} 0.01<P<0.001 ;{ }^{* * * *} P<0.001$. 
plays an important role in inducing immune responses and viral entry. Mutation of the $\mathrm{S}$ gene may lead to different mechanisms of virus invasion, which may help elucidate the pathogenesis and immune evasion of PEDV. As SARS-CoV utilizes varying endocytic routes to invade different cells [23, 24], we wondered whether PEDVs can enter cells through different pathways. Burkard et al. clarified that coronavirus entered cells through the endosome/lysosome pathway and was proteolytic dependent. The furin cleavage site just upstream of the fusion peptide (FP) of the $\mathrm{S}$ protein was the key to determining the fusion site of the viral membrane [32]. While the S protein of PEDV does not have the furin cleavage site, a conserved arginine just upstream of the putative FP as the potential cleavage site can be cleaved by trypsin [65]. Whether the theory mentioned above is applicable to PEDV thus needs further study. Here, we explored the GI and GII subtype pathways of PEDV entry into Vero and IPEC-J2 cells, respectively, and the transportation route after internalization. Our results showed that two the subtypes of PEDV utilized clathrin-, caveolae-, and lipid raft-mediated endocytosis to enter the Vero and IPECJ2 cells, but the utilization efficiency of each endocytic pathway varied depending on the different genotypes and types of cells.

To describe the dynamic curve of PEDV entry, the appropriate viral scavenger is extremely important to remove virus particles effectively adsorbed on the cell surface. We compared the effects of citrate buffer $(\mathrm{pH}$ 3.0) with proteinase $\mathrm{K}(1 \mathrm{mg} / \mathrm{mL})$, and the latter exhibited a stronger capacity to remove viruses. The results of dynamic invasion showed that the virus invaded Vero cells $100 \%$ within $60 \mathrm{~min}$, while the invasion efficiency of the IPEC-J2 cells was only approximately $30 \%$. Although IPEC-J2 cells are considered the host cells of PEDV, the cell lines cultured in vitro lost their polar growth state in vivo [66], which possibly affects the viral recognition and reduces the infection efficiency of the virus. GDS01 showed a lower invasion rate than GDS09, but there was no significant difference.

Dynamin II, a GTPase, plays an important role in endocytosis by pinching the endocytic vesicles off the plasma and is necessary in clathrin- and caveolae-mediated endocytosis. We found that PEDV entry is dynamin IIdependent, although the sensitivity of the GDS01 and GDS09 strains to dynasore varied. Considering the low specificity of chemistry inhibitor, dominant negative mutant and siRNA-mediated knockdown of dynamin II were carried out to evaluate dynamin II for PEDV infection. Both the GDS01 and GDS09 strains were inhibited by siDynamin II with no significant difference.

Clathrin-mediated endocytosis is a classical and commonly used pathway for most enveloped viruses. Many coronaviruses use CME to enter cells, such as SARS-CoV entry into HepG2 cells and COS7 cells and PHEV entry into Neuro-2a cells $[23,35]$. To ascertain whether PEDV utilized CME to enter cells, the chemistry inhibitor CPZ was used to prevent clathrin assembly and further block CME. Clathrin is composed of light chain (CLC) and heavy chain $(\mathrm{CHC})$ which form clathrin lattices under the interaction of AP-2 and EPS 15. Both CPZ pre-treatment and siRNA-mediated knockdown of $\mathrm{CHC}$ and EPS 15 can significantly reduce the invasion rate of PEDV into cells, with no significant difference between the GDS01 and GDS09 strains. Dominant negative mutants can provide a more specific method to study endocytic pathways by separating the prototype protein from their interaction regulatory factors. In this study, we also showed that cells overexpressing dominant negative mutant of EPS 15 were barely infected with PEDV but cells overexpressing wild-type EPS 15 were infected as normal. However, the inhibition of endocytosis by overexpressing dominant negative mutants may be compensated through other clathrin-independent endocytic pathways. When viruses enter cells through CME, they are carried by clathrincoated vesicles. Co-localization of viral particles and $\mathrm{CHC}$ indicated that PEDV entry relies on CME.

Although caveolae and lipid rafts have the same components, such as caveolin-1, GM1, and cholesterol, they are two completely different endocytic pathways. Before investigating whether PEDV can use these two pathways to enter cells, we first examined whether PEDV invasion depends on cholesterol. The cholesterol inhibitors nystatin and $M \beta C D$ had significant inhibitory effects on PEDV entry. Nystatin had higher inhibitory effects on GDS09 entry than GDS01. The inhibitory effects of $\mathrm{M} \beta C D$ on Vero cells were similar for GDS09 and GDS01 strains. M $\beta C D$ effects were lower on GDS09 than GDS01 in IPEC-J2 cells. We hypothesized that GDS01 cell invasion mainly depended on cholesterol on the cell surface, while GDS09 depended on the presence of cholesterol on the cell surface and cholesterol synthesis. Exogenous cholesterol supplementation also confirmed the importance of cholesterol in PEDV entry. Endocytic vesicles formed in the caveolae-mediated pathway were coated with caveolin-1, which plays a critical role in the process. Dominant negative mutant, RNA interference, and the cellular co-localization of caveolin-1 with viral particles provided further evidence that PEDV entry needed caveolin-1. Collectively, both subtypes of PEDV entered the Vero and IPEC-J2 cells through caveolae-mediated endocytosis. However, Park et al. [33] showed that PEDV entry was independent of caveolae-coated pit assembly by treating Vero cells with nystatin. The different results may be explained by different operational details. Firstly, nystatin was used before and during the incubation of 
PEDV in this study, while only before incubation in the research of Park et al. The concentrations of nystatin used in the two studies were different. The highest concentration of nystatin used in Park's research was $20 \mu \mathrm{M}$ [33], while the highest concentration we used was $30 \mu \mathrm{M}$ in Vero cells. When the concentration is $10 \mu \mathrm{M}$, nystatin does not inhibit the entry of PEDV, which is consistent with Park's results. Secondly, Park et al. added methyl cellulose to block second-cycle infection [33], while we added nothing except trypsin in medium. Whether these reasons cause two different results needs further study.

Lipid raft acted as a platform for cell signal transduction and viral invasion, distributed in an island form on the plasma membrane of cells, and was isolated by sucrose density gradient centrifugation. Western blotting analysis showed that PEDV $\mathrm{N}$ protein located in the lipid raft (upper layer) with caveolin-1 in the cells. As shown in Figure 6B, PEDV N protein is also present in the bottom layer when infected with IPEC-J2 cells, which may be due to the different composition of the plasma membranes of the two kinds of cells.

We demonstrated that PEDV GI subtype GDS09 and GII subtype GDS01 strains could enter Vero and IPECJ2 cells via the clathrin-, caveolae-, and lipid raft-mediated endocytosis pathways. Furthermore, we also found that the invasion efficiency of the two strains was different with different endocytosis pathway. These differences between GDS01 and GDS09 strains may be due to the difference of $\mathrm{S}$ gene especially the $\mathrm{S} 1$ region of $\mathrm{S}$ gene (homology was about 92\%), which is responsible for cell entry and membrane fusion by binding with receptor. The difference of gene may lead to the difference of binding ability or affinity between $\mathrm{S}$ protein and receptor, thus leading to the different utilization or initiation efficiency of different endocytosis pathways. However, whether the different gene sequence causes different invasion efficiency between GDS01 and GDS09 strains needs further study.

After internalization, viral particles are transported by specific endosomes for membrane fusion. The classical transit route is the endo-/lysosomal pathway, in which endocytic cargoes are transported along endocytic vesicles, early endosomes, and late endosomes-lysosomes. Park et al. have confirmed that $\mathrm{NH}_{4} \mathrm{Cl}$ and Baf-A1 could inhibit PEDV entry [33], which is consistent with our results, but needs to be confirmed by different methods. In this study, in addition to chemical inhibitors, we also used siRNA interference and cellular localization of virus particles to identify the role of $\mathrm{pH}$ and endosomes. The results of this study revealed that PEDV entry relied on low $\mathrm{pH}$, which means that internalized PEDV particles are transported to endosomes and lysosomes, as demonstrated by the co-localization of viral particles with EEA1, Rab7, and LAMP1. Liu et al. [67] reported that PEDV $S$ protein was activated by lysosomal cysteine proteases to activate PEDV entry. However, based on the data, we could not conclude that membrane fusion occurred at the lysosomes; more technical methods are necessary to demonstrate the mechanism.

In conclusion, studying the internalization and intracellular trafficking mechanism of PEDV are important to understand viral pathogenesis and benefit to the development of future therapies strategies. This study demonstrated that both the GI and GII subtypes of PEDV enter Vero and IPEC-J2 cells via the clathrin-, caveolae-, and lipid raft-mediated endocytosis pathways, but the efficiency of each endocytosis pathway varies depending on the different genotypes and types of cells. The internalized PEDV entered the lysosomes through the early and late endosomes. The results of this study provide a theoretical basis for the further understanding of PEDV pathogenesis to find new targets of antiviral drugs.

\section{Supplementary information}

Supplementary information accompanies this paper at https://doi. org/10.1186/s13567-020-0739-7.

Additional file 1. Dynamin II is involved in PEDV entry. (A) Vero cells and IPEC-J2 cells were treated with different concentrations of dynasore at $37^{\circ} \mathrm{C}$ for $4 \mathrm{~h}$. CCK-8 solution was added to each well at $37^{\circ} \mathrm{C}$ for $1 \mathrm{~h}$, and absorptions of $450 \mathrm{~nm}$ were detected. DMSO was used as a negative control. (B) The Vero cells and IPEC-J2 cells were transfected with siDyn, and the second transfection was carried out at $24 \mathrm{~h}$ after the first transfection. The inference efficiency was detected by qRT-PCR and Western blotting at $48 \mathrm{~h}$ after the first transfection. Ctrl means control. ${ }^{* *} 0.05<P<0.01$; ${ }^{* * *} 0.01<P<0.001$; ${ }^{* * * *} P<0.001$.

Additional file 2. Clathrin-mediated endocytosis is involved in PEDV entry. (A) Vero cells and IPEC-J2 cells were treated with different concentrations of $\mathrm{CPZ}$ at $37^{\circ} \mathrm{C}$ for $4 \mathrm{~h}$. CCK-8 solution was added to each well at $37{ }^{\circ} \mathrm{C}$ for $1 \mathrm{~h}$, and absorptions of $450 \mathrm{~nm}$ were detected. Double-distilled water was used as a negative control. (B, C) The Vero cells and IPEC-J2 cells were transfected with $\mathrm{SiCHC}$ and siEPS15, and the second transfection was carried out at $24 \mathrm{~h}$ after the first transfection. The inference efficiency was detected by qRT-PCR and Western blotting at $48 \mathrm{~h}$ after the first transfection. Ctrl means control. ${ }^{*} P<0.05 ;{ }^{* *} 0.05<P<0.01 ;{ }^{* * *} 0.01<P<0.001$; **** $P<0.001$.

Additional file 3. Endocytic drugs inhibited PEDV entry into Vero cells. Cells were seeded in 12-well plates until confluence. Cells were pre-treated with $30 \mu \mathrm{M} \mathrm{CPZ,} 3 \mathrm{mM} \mathrm{M \beta CD}, 30 \mu \mathrm{M}$ Nystatin, $50 \mathrm{mM} \mathrm{NH} 4 \mathrm{Cl}$ and $200 \mathrm{nM}$ Baf $\mathrm{A} 1$ respectively, at $37^{\circ} \mathrm{C}$ for $1 \mathrm{~h}$ and incubated with GDS01 (A) and GDS09 (B) strains for $1 \mathrm{~h}$. Double-distilled water was used as a negative control. The cells were collected at 9 hpi and detected by immunofluorescence staining against the PEDV S protein (green). Nuclei were stained with DAPI (blue). Scale bars indicate $100 \mu \mathrm{m}$.

Additional file 4. Endocytic drugs inhibited PEDV entry into IPEC-J2 cells. Cells were seeded in 12-well plates until confluence. Cells were pre-treated with $50 \mu \mathrm{M} \mathrm{CPZ}, 1.5 \mathrm{mM} \mathrm{MBCD}, 50 \mu \mathrm{M}$ Nystatin, $50 \mathrm{mM}$ $\mathrm{NH} 4 \mathrm{Cl}$ and $400 \mathrm{nM}$ Baf $\mathrm{A} 1$ respectively, at $37^{\circ} \mathrm{C}$ for $1 \mathrm{~h}$ and incubated with GDS01 (A) and GDS09 (B) strains for 1 h. Double-distilled water was used as a negative control. The cells were collected at $15 \mathrm{hpi}$ and detected by immunofluorescence staining against the PEDV S protein (green). Nuclei were stained with DAPI (blue). Scale bars indicate $100 \mu \mathrm{m}$. 


\begin{abstract}
Additional file 5. PEDV entry relies on cholesterol and caveolin-1. (A, B) Vero cells (A) and IPEC-J2 cells (B) were treated with different concentrations of $\mathrm{MBCD}$ at $37^{\circ} \mathrm{C}$ for $4 \mathrm{~h}$, respectively. CCK-8 solution was added to each well at $37^{\circ} \mathrm{C}$ for $1 \mathrm{~h}$, and absorptions of $450 \mathrm{~nm}$ were detected. Double-distilled water was used as a negative control. (C) The Vero cells and IPEC-J2 cells were treated with different concentrations of nystatin at $37^{\circ} \mathrm{C}$ for $4 \mathrm{~h}$, respectively. CCK-8 solution was added to each well at $37^{\circ} \mathrm{C}$ for $1 \mathrm{~h}$, and absorptions of $450 \mathrm{~nm}$ were detected. DMSO was used as a negative control. (D) The Vero cells and IPEC-J2 cells were transfected with siCav, and the second transfection was carried out at $24 \mathrm{~h}$ after the first transfection. The inference efficiency was detected by qRT-PCR and Western blotting at $24 \mathrm{~h}$ after the second transfection. Ctrl means control. (E) The Vero cells (up) and IPEC-J2 cells (down) were treated with MBCD at $37^{\circ} \mathrm{C}$ for $1 \mathrm{~h}$, and the amount of cholesterol was detected following the instructions of the cholesterol quantitative kit (AmyJet Scientific). A histogram was created via the fluorescence density. The error bars represent the SD of 10 figures from three independent experiments. ${ }^{*} P<0.05$; ${ }^{* *} 0.05<P<0.01 ; * * 0.01<P<0.001 ; * * * * 00.001$.
\end{abstract}

\section{Additional file 6. Internalized PEDV traffics to lysosomes via}

endosomes. (A, B) Vero cells (A) and IPEC-J2 cells (B) were treated with different concentrations of $\mathrm{NH} 4 \mathrm{Cl}$ and $\mathrm{Baf} \mathrm{A} 1$ at $37^{\circ} \mathrm{C}$ for $4 \mathrm{~h}$, respectively. CCK-8 solution was added to each well at $37^{\circ} \mathrm{C}$ for $1 \mathrm{~h}$, and absorptions of $450 \mathrm{~nm}$ were detected. Double-distilled water and DMSO were used as negative controls, respectively. (C-D) The Vero cells (C) and IPEC-J2 cells (D) were transfected with siRab7 and siVPS39, respectively, and the second transfection was carried out at $24 \mathrm{~h}$ after the first transfection. The inference efficiency was detected by qRT-PCR at $24 \mathrm{~h}$ after the second transfection. ${ }^{* *} 0.05<P<0.01 ;{ }^{* * *} 0.01<P<0.001 ;{ }^{* * *} P<0.001$.

\section{Abbreviations}

PEDV: porcine epidemic diarrhea virus; CME: clathrin-mediated endocytosis; CCPs: clathrin-coated pits; CCVs: clathrin-coated vesicles; SARS-CoV: severe acute respiratory syndrome coronavirus; $\mathrm{MHV}$ : murine hepatitis virus; $\mathrm{HCoVs}$ : human coronavirus; MERS-CoV: middle east respiratory syndrome coronavirus; FIPV: feline infectious peritonitis virus; CHC: clathrin heavy chain; CLC: clathrin light chain; MVB: multivesicular body; LAMP1: lysosomal associated membrane protein 1; CPZ: chlorpromazine; $M \beta C D$ : methyl- $\beta$-cyclodextrin; Baf A1: bafilomycin A1; CTB: cholera toxin B subunit; Trf: transferrin; MOl: multiplicity of infection; PMSF: phenylmethanesulfonyl fluoride.

\section{Acknowledgements}

We would like to thank Prof. Qiang Yang, College of Veterinary Medicine, Nanjing Agricultural University, China, for providing us with IPEC-J2 cells. We would also like to thank Prof. Mark McNiven, Mayo Center for Biomedical Discovery, USA, for providing us with overexpression vector of wild-type and domain negative mutant of dynamin II and Caveolin-1.

\section{Authors' contributions}

Conceived and designed the experiments: YC, CX, XW. Performed the experiments: XW, GS, TW. Analyzed the data: XW. Wrote the paper: XW, CX, YC. Provided scientific input:YC. All authors read and approved the final manuscript.

\section{Funding}

This study was supported by the National Key Research and Development Program of China (No. 2016YFD0500101).

\section{Competing interests}

The authors declare that they have no competing interests.

Received: 5 October 2019 Accepted: 7 January 2020

Published online: 10 February 2020

\section{References}

1. Chasey D, Cartwright SF (1978) Virus-like particles associated with porcine epidemic diarrhoea. Res Vet Sci 25:255-256

2. Jung K, Saif LJ (2015) Porcine epidemic diarrhea virus infection: etiology, epidemiology, pathogenesis and immunoprophylaxis. Vet J 204:134-143
3. Lee C (2015) Porcine epidemic diarrhea virus: an emerging and reemerging epizootic swine virus. Virol J 12:193

4. Song D, Moon H, Kang B (2015) Porcine epidemic diarrhea: a review of current epidemiology and available vaccines. Clin Exp Vaccine Res 4:166-176

5. Song D, Park B (2012) Porcine epidemic diarrhoea virus: a comprehensive review of molecular epidemiology, diagnosis, and vaccines. Virus Genes 44:167-175

6. Li W, Li H, Liu Y, Pan Y, Deng F, Song Y, Tang X, He Q (2012) New variants of porcine epidemic diarrhea virus, China, 2011. Emerg Infect Dis 18:1350-1353

7. Sun RQ, Cai RJ, Chen YQ, Liang PS, Chen DK, Song CX (2012) Outbreak of porcine epidemic diarrhea in suckling piglets, China. Emerg Infect Dis 18:161-163

8. Wang J, Zhao P, Guo L, Liu Y, Du Y, Ren S, Li J, Zhang Y, Fan Y, Huang B, Liu S, Wu J (2013) Porcine epidemic diarrhea virus variants with high pathogenicity, China. Emerg Infect Dis 19:2048-2049

9. Vlasova AN, Marthaler D, Wang QH, Culhane MR, Rossow KD, Rovira A, Collins J, Saif LJ (2014) Distinct characteristics and complex evolution of PEDV strains, North America, May 2013-February 2014. Emerg Infect Dis 20:1620-1628

10. Wang D, Fang L, Xiao S (2016) Porcine epidemic diarrhea in China. Virus Res 226:7-13

11. Temeeyasen G, Sinha A, Gimenez-Lirola LG, Zhang JQ, Pineyro PE (2018) Differential gene modulation of pattern-recognition receptor TLR and RIG-I-like and downstream mediators on intestinal mucosa of pigs infected with PEDV non S-INDEL and PEDV S-INDEL strains. Virology 517:188-198

12. Li L, Fu F, Xue M, Chen W, Liu J, Shi H, Chen J, Bu Z, Feng L, Liu P (2017) IFN-lambda preferably inhibits PEDV infection of porcine intestinal epithelial cells compared with IFN-alpha. Antiviral Res 140:76-82

13. Wang P, Zhu J, Liu X, Guo J, Gu X, Ruan W (2019) Isolation and recombinant analysis of variants of porcine epidemic diarrhea virus strains from Beijing, China. VirusDisease 30:294-301

14. Wen Z, Xu Z, Zhou Q, Li W, Wu Y, Du Y, Chen L, Zhang Y, Xue C, Cao Y (2018) Oral administration of coated PEDV-loaded microspheres elicited PEDV-specific immunity in weaned piglets. Vaccine 36:6803-6809

15. Li Q, Xu Z, Wu T, Peng O, Huang L, Zhang Y, Xue C, Wen Z, Zhou Q, Cao Y (2018) A flagellin-adjuvanted PED subunit vaccine improved protective efficiency against PEDV variant challenge in pigs. Vaccine 36:4228-4235

16. Yamauchi Y, Helenius A (2013) Virus entry at a glance. J Cell Sci 126:1289-1295

17. Kalia M, Jameel S (2011) Virus entry paradigms. Amino Acids 41:1147-1157

18. Kaksonen M, Roux A (2018) Mechanisms of clathrin-mediated endocytosis. Nat Rev Mol Cell Biol 19:313-326

19. Doherty GJ, McMahon HT (2009) Mechanisms of endocytosis. Annu Rev Biochem 78:857-902

20. Nicola AV, Aguilar HC, Mercer J, Ryckman B, Wiethoff CM (2013) Virus entry by endocytosis. Adv Virol 2013:469538

21. Pelkmans L, Helenius A (2002) Endocytosis via caveolae. Traffic 3:311-320

22. Lajoie P, Nabi IR (2007) Regulation of raft-dependent endocytosis. J Cell Mol Med 11:644-653

23. Inoue $Y$, Tanaka N, Tanaka Y, Inoue S, Morita K, Zhuang M, Hattori T, Sugamura K (2007) Clathrin-dependent entry of severe acute respiratory syndrome coronavirus into target cells expressing ACE2 with the cytoplasmic tail deleted. J Virol 81:8722-8729

24. Wang HL, Yang P, Liu KT, Guo F, Zhang YL, Zhang GY, Jiang CY (2008) SARS coronavirus entry into host cells through a novel clathrin- and caveolaeindependent endocytic pathway. Cell Res 18:290-301

25. Li GM, Li YG, Yamate M, Li SM, Ikuta K (2007) Lipid rafts play an important role in the early stage of severe acute respiratory syndrome-coronavirus life cycle. Microbes Infect 9:96-102

26. Eifart $\mathrm{P}$, Ludwig K, Bottcher C, de Haan CA, Rottier PJ, Korte T, Herrmann A (2007) Role of endocytosis and low pH in murine hepatitis virus strain A59 cell entry. J Virol 81:10758-10768

27. Qiu ZZ, Hingley ST, Simmons G, Yu C, Das Sarma J, Bates P, Weiss SR (2006) Endosomal proteolysis by cathepsins is necessary for murine coronavirus mouse hepatitis virus type 2 spike-mediated entry. J Virol 80:5768-5776

28. Sturman LS, Ricard CS, Holmes KV (1985) Proteolytic cleavage of the E2 glycoprotein of murine coronavirus: activation of cell-fusing activity of 
virions by trypsin and separation of two different $90 \mathrm{~K}$ cleavage fragments. JVirol 56:904-911

29. Milewska A, Nowak P, Owczarek K, Szczepanski A, Zarebski M, Hoang A, Berniak K, Wojarski J, Zeglen S, Baster Z, Rajfur Z, Pyrc K (2018) Entry of human coronavirus NL63 into the cell. J Virol 92:01933-17

30. Nomura R, Kiyota A, Suzaki E, Kataoka K, Ohe Y, Miyamoto K, Senda T, Fujimoto T (2004) Human coronavirus 229E binds to CD13 in rafts and enters the cell through caveolae. JVirol 78:8701-8708

31. Freeman MC, Peek CT, Becker MM, Smith EC, Denison MR (2014) Coronaviruses induce entry-independent, continuous macropinocytosis. MBio 5:e01340-01314

32. Burkard C, Verheije MH, Wicht O, van Kasteren SI, van Kuppeveld FJ, Haagmans BL, Pelkmans L, Rottier PJM, Bosch BJ, de Haan CAM (2014) Coronavirus cell entry occurs through the endo-/lysosomal pathway in a proteolysis-dependent manner. PLoS Pathog 10:e1004502

33. Park JE, Cruz DJM, Shin HJ (2014) Clathrin- and serine proteases-dependent uptake of porcine epidemic diarrhea virus into Vero cells. Virus Res 191:21-29

34. Gong L, Lin Y, Qin J, Li Q, Xue C, Cao Y (2018) Neutralizing antibodies against porcine epidemic diarrhea virus block virus attachment and internalization. Virol J 15:133

35. Li Z, Zhao K, Lan YG, Lv XL, Hu SY, Guan JY, Lu HJ, Zhang J, Shi JC, Yang YW, Song DG, Gao F, He WQ (2017) Porcine hemagglutinating encephalomyelitis virus enters neuro-2a cells via clathrin-mediated endocytosis in a Rab5-, cholesterol-, and pH-dependent manner. J Virol 91:e01083-17

36. Luo X, Guo L, Zhang J, Xu Y, Gu W, Feng L, Wang Y (2017) Tight junction protein occludin is a porcine epidemic diarrhea virus entry factor. J Virol 91:e00202-17

37. Henley JR, Krueger EW, Oswald BJ, McNiven MA (1998) Dynamin-mediated internalization of caveolae. J Cell Biol 141:85-99

38. Wang QC, Liu J, Duan X, Cui XS, Kim NH, Xiong B, Sun SC (2015) The Dynamin 2 inhibitor Dynasore affects the actin filament distribution during mouse early embryo development. J Reprod Dev 61:49-53

39. Abdulkarim AS, Cao H, Huang B, McNiven MA (2003) The large GTPase dynamin is required for hepatitis $B$ virus protein secretion from hepatocytes. J Hepatol 38:76-83

40. Huang IC, Bosch BJ, Li F, Li WH, Lee KH, Ghiran S, Vasilieva N, Dermody TS, Harrison SC, Dormitzer PR, Farzan M, Rottier PJM, Choe H (2006) SARS coronavirus, but not human coronavirus NL63, utilizes cathepsin L to infect ACE2-expressing cells. J Biol Chem 281:3198-3203

41. Vallee RB, Herskovits JS, Aghajanian JG, Burgess CC, Shpetner HS (1993) Dynamin, a GTPase involved in the initial stages of endocytosis. Ciba Found Symp 176:185-193 (discussion 193-187)

42. Shi BJ, Liu CC, Zhou J, Wang SQ, Gao ZC, Zhang XM, Zhou B, Chen PY (2016) Entry of classical swine fever virus into PK-15 cells via a pHdynamin-, and cholesterol-dependent, clathrin-mediated endocytic pathway that requires Rab5 and Rab7. J Virol 90:9194-9208

43. Navaroli DM, Bellve KD, Standley C, Lifshitz LM, Cardia J, Lambright D, Leonard D, Fogarty KE, Corvera S (2012) Rabenosyn-5 defines the fate of the transferrin receptor following clathrin-mediated endocytosis. Proc Natl Acad Sci U S A 109:E471-480

44. Hussain KM, Leong KL, Ng MM, Chu JJ (2011) The essential role of clathrin-mediated endocytosis in the infectious entry of human enterovirus 71. J Biol Chem 286:309-321

45. Benmerah A, Bayrou M, Cerf-Bensussan N, Dautry-Varsat A (1999) Inhibition of clathrin-coated pit assembly by an Eps15 mutant. J Cell Sci 112:1303-1311

46. Benmerah A, Lamaze C, Bègue B, Schmid SL, Dautry-Varsat A, Cerf-Bensussan N (1998) AP-2/Eps15 interaction is required for receptor-mediated endocytosis. J Cell Biol 140:1055-1062

47. Scarmato P, Kirchhausen T (1990) Analysis of clathrin light chain-heavy chain interactions using truncated mutants of rat liver light chain LCB3. J Biol Chem 265:3661-3668

48. Marquardt D, Heberle FA, Greathouse DV, Koeppe RE, Standaert RF, Van Oosten BJ, Harroun TA, Kinnun JJ, Williams JA, Wassall SR, Katsaras J (2016) Lipid bilayer thickness determines cholesterol's location in model membranes. Soft Matter 12:9417-9428
49. Danthi P, Chow M (2004) Cholesterol removal by methyl-beta-cyclodextrin inhibits poliovirus entry. J Virol 78:33-41

50. Marjomaki V, Pietiainen V, Matilainen H, Upla P, Ivaska J, Nissinen L, Reunanen $\mathrm{H}$, Huttunen P, Hyypia T, Heino J (2002) Internalization of echovirus 1 in caveolae. J Virol 76:1856-1865

51. Rituper B, Chowdhury HH, Jorgacevski J, Coorssen JR, Kreft M, Zorec R (2013) Cholesterol-mediated membrane surface area dynamics in neuroendocrine cells. Biochim Biophys Acta 1831:1228-1238

52. Van Leeuwen MR, Golovina EA, Dijksterhuis J (2009) The polyene antimycotics nystatin and filipin disrupt the plasma membrane, whereas natamycin inhibits endocytosis in germinating conidia of Penicillium discolor. J Appl Microbiol 106:1908-1918

53. Callera GE, Bruder-Nascimento T, Touyz RM (2017) Assessment of caveolae/lipid rafts in isolated cells. Methods Mol Biol 1527:251-269

54. Krause MR, Regen SL (2014) The structural role of cholesterol in cell membranes: from condensed bilayers to lipid rafts. Acc Chem Res 47:3512-3521

55. Walker WA, Tarannum M, Vivero-Escoto JL (2016) Cellular endocytosis and trafficking of Cholera toxin B-modified mesoporous silica nanoparticles. J Mater Chem B 4:1254-1262

56. Tachikawa M, Morone N, Senju Y, Sugiura T, Hanawa-Suetsugu K, Mochizuki A, Suetsugu S (2017) Measurement of caveolin-1 densities in the cell membrane for quantification of caveolar deformation after exposure to hypotonic membrane tension. Sci Rep 7:7794

57. Zhu YZ, Xu QQ, Wu DG, Ren H, Zhao P, Lao WG, Wang Y, Tao QY, Qian XJ, Wei YH, Cao MM, Qi ZT (2012) Japanese encephalitis virus enters rat neuroblastoma cells via a pH-dependent, dynamin and caveola-mediated endocytosis pathway. J Virol 86:13407-13422

58. Zhu YZ, Wu DG, Ren H, Xu QQ, Zheng KC, Chen W, Chen SL, Qian XJ, Tao QY, Wang Y, Zhao P, Qi ZT (2015) The role of lipid rafts in the early stage of Enterovirus 71 infection. Cell Physiol Biochem 35:1347-1359

59. Elkin SR, Lakoduk AM, Schmid SL (2016) Endocytic pathways and endosomal trafficking: a primer. Wien Med Wochenschr 166:196-204

60. Misinzo G, Delputte PL, Nauwynck HJ (2008) Inhibition of endosomelysosome system acidification enhances porcine circovirus 2 infection of porcine epithelial cells. J Virol 82:1128-1135

61. Ochiai H, Sakai S, Hirabayashi T, Shimizu Y, Terasawa K (1995) Inhibitory effect of bafilomycin A1, a specific inhibitor of vacuolar-type proton pump, on the growth of influenza A and B viruses in MDCK cells. Antiviral Res 27:425-430

62. Podinovskaia M, Spang A (2018) The endosomal network: mediators and regulators of endosome maturation. Prog Mol Subcell Biol 57:1-38

63. Hyttinen JM, Niittykoski M, Salminen A, Kaarniranta K (2013) Maturation of autophagosomes and endosomes: a key role for Rab7. Biochim Biophys Acta 1833:503-510

64. Wen Z, Li J, Zhang Y, Zhou Q, Gong L, Xue C, Cao Y (2018) Genetic epidemiology of porcine epidemic diarrhoea virus circulating in China in 2012-2017 based on spike gene. Transbound Emerg Dis 65:883-889

65. Wicht O, Li W, Willems L, Meuleman TJ, Wubbolts RW, van Kuppeveld FJ, Rottier PJ, Bosch BJ (2014) Proteolytic activation of the porcine epidemic diarrhea coronavirus spike fusion protein by trypsin in cell culture. J Virol 88:7952-7961

66. Li L, Fu F, Guo S, Wang H, He X, Xue M, Yin L, Feng L, Liu P (2019) Porcine intestinal enteroids: a new model for studying enteric coronavirus porcine epidemic diarrhea virus infection and the host innate response. J Virol 93:e01682-18

67. Liu C, Ma YM, Yang Y, Zheng Y, Shang J, Zhou YS, Jiang SB, Du LY, Li JR, Li F (2016) Cell entry of porcine epidemic diarrhea coronavirus is activated by lysosomal proteases. J Biol Chem 291:24779-24786

\section{Publisher's Note}

Springer Nature remains neutral with regard to jurisdictional claims in published maps and institutional affiliations. 